\title{
External fertilization is orchestrated by a pH-regulated soluble adenylyl cyclase controlling sperm motility and chemotaxis
}

\author{
H.G. Körschen ${ }^{1 *}$, H. Hamzeh ${ }^{1,2^{*}}$, R. Pascal ${ }^{1}$, L. Alvarez ${ }^{1}$, W. Bönigk ${ }^{1}$, N. Kaur ${ }^{3}$, L.R. Levin ${ }^{3}$, \\ J. Buck ${ }^{3}$, C. Kambach ${ }^{4}$, M. Michino ${ }^{7}$, A. Jennings ${ }^{7}$, A.Sato ${ }^{7}$, R. Seifert ${ }^{1,2}$, T. Strünker ${ }^{1,2,5}$, C.
} Steegborn $^{4}$, and U.B. Kaupp $p^{1,2,6}$

${ }^{1}$ Center of Advanced European Studies and Research (caesar), Department Molecular Sensory Systems, Ludwig-Erhard-Allee 2, 53175 Bonn, Germany.

${ }^{2}$ Marine Biological Laboratory, 7 MBL Street, Woods Hole, USA.

${ }^{3}$ Department of Pharmacology, Weill Cornell Medicine, New York, USA.

${ }^{4}$ Department of Biochemistry, University of Bayreuth, 95440 Bayreuth, Germany;

${ }^{5}$ University Hospital Münster, University of Münster, Center of Reproductive Medicine and Andrology,

Albert-Schweitzer-Campus 1, 48149 Münster, Germany.

${ }^{6}$ University of Bonn, Life \& Medical Sciences Institute (LIMES), Carl-Troll-Str. 31, 53115 Bonn, Germany

${ }^{7}$ Tri-Institutional Therapeutics Discovery Institute, 413 East $69^{\text {th }}$ Street, New York, USA

*Authors contributed equally to this work.

Send correspondence to:

U. Benjamin Kaupp

Center of Advanced European Studies and Research

Molecular Sensory Systems

Ludwig-Erhard-Allee 2

53175 Bonn, Germany

Tel.: ++49228-9656-100, Fax: ++49228-9656-9273

e-mail: u.b.kaupp@caesar.de 


\section{ABSTRACT}

The reaction of $\mathrm{CO}_{2}$ with $\mathrm{H}_{2} \mathrm{O}$ to form $\mathrm{HCO}_{3}{ }^{-}$and $\mathrm{H}^{+}$is one of the most important chemical equilibria in cells. In mammalian sperm, a soluble adenylyl cyclase (sAC) serves as cellular $\mathrm{HCO}_{3}{ }^{-}$sensor that conveys the equilibrium state via cAMP synthesis to cAMP-signaling molecules. The function of sAC and cAMP in non-mammalian sperm is largely unknown. Here, we identify sAC orthologs in sea urchin and salmon sperm that, surprisingly, are activated by alkaline $\mathrm{pH}$ rather than $\mathrm{HCO}_{3}{ }^{-}$. Two amino-acid residues required for $\mathrm{HCO}_{3}{ }^{-}$ binding of mammalian sAC are lacking in pH-regulated sAC. Orthologs identified in ten other phyla are also lacking either one of these key residues, suggesting that $\mathrm{pH}$ control is widespread among non-mammalian metazoan. The $\mathrm{pH}$-sensitive sAC controls several functions of sperm from external fertilizers. Upon spawning, alkalization triggers cAMP synthesis and, thereby, activates motility of quiescent sperm. Egg-derived chemoattractants also alkalize sperm and elevate cAMP, which then-modulates pacemaker HCN channels to trigger a chemotactic $\mathrm{Ca}^{2+}$ response. Finally, the sAC and the voltage- and cAMP-activated $\mathrm{Na}^{+} / \mathrm{H}^{+}$exchanger sNHE mutually control each other. A picture of evolutionary significance is emerging: motility and sensory signaling of sperm from both internal and external fertilizers rely on cAMP, yet, their sAC is regulated by $\mathrm{HCO}_{3}{ }^{-}$or $\mathrm{pH}_{\mathrm{i}}$, respectively. Acidification of aquatic habitats due to climate change may adversely affect $\mathrm{pH}$-sensing by sAC and thereby sexual reproduction in the sea.

\section{Keywords: cAMP, signaling, sperm, fertilization, pH, Calcium}




\section{Statement of significance}

Adenylyl cyclases synthesize cAMP, a prominent cellular messenger. A bicarbonate-sensitive AC family member, soluble AC (sAC), is tied to the chemical equilibrium: $\mathrm{H}_{2} \mathrm{O}+\mathrm{CO}_{2} \leftrightarrow$ $\mathrm{HCO}_{3}{ }^{-}$(bicarbonate) $+\mathrm{H}^{+}$. The sAC is required for fertilization: Mammals lacking sAC are infertile and sperm immotile. We now identify a new sAC form in sperm of non-mammalian animals that reproduce in the sea. This novel sAC is activated at alkaline $\mathrm{pH}$ rather than bicarbonate. It controls sperm motility and chemotaxis. The switch from $\mathrm{HCO}_{3}{ }^{-}$to $\mathrm{pH}$ rests on substitution of two amino-acids, which represents an adaptation to aquatic environments low in bicarbonate. Acidification of aquatic habitats due to climate change may adversely affect sAC activity and, thereby, fertilization.

\section{Introduction}

Cyclic AMP is a ubiquitous cellular messenger that orchestrates many physiological processes. In metazoans, it is synthesized by two different types of adenylyl cyclases: transmembrane AC (tmAC) and soluble AC (sAC). The sACs orthologs studied so far are directly regulated by bicarbonate $\left(\mathrm{HCO}_{3}{ }^{-}\right)$and calcium $\left(\mathrm{Ca}^{2+}\right)(1)$. Cellular $\mathrm{HCO}_{3}{ }^{-}$levels are determined by the chemical equilibrium:

$$
\mathrm{CO}_{2}+\mathrm{H}_{2} \mathrm{O} \leftrightharpoons \mathrm{HCO}_{3}^{-}+\mathrm{H}^{+}
$$

The sAC monitors the status of this equilibrium and translates changes into a cAMP signal that controls downstream targets directly or via phosphorylation by protein kinase A (PKA) (1). Its key role as $\mathrm{HCO}_{3}{ }^{-}$sensor has been firmly established in mammalian sperm. Soluble AC may also serve as $\mathrm{pH}_{\mathrm{i}}$ sensor indirectly via the $\mathrm{CO}_{2} / \mathrm{HCO}_{3}{ }^{-} / \mathrm{H}^{+}$equilibrium (1). The $\mathrm{HCO}_{3}^{-}$ concentration (15-25 mM) in semen and the oviduct stimulates cAMP synthesis by sAC, which initiates and modulates sperm motility. Moreover, cAMP synthesis by sAC initiates an 
essential maturation process, called capacitation (2). Deletion of the genes encoding sAC or the regulatory and catalytic subunits of PKA renders sperm immotile and male mice infertile (3-5). In humans, frame-shift mutations in the adcyl0 gene encoding sAC also cause male infertility due to immotile sperm (6).

Soluble AC and potential cAMP-signaling targets have also been identified in sperm of external fertilizers ranging from marine invertebrates to fish (7-12). Although its properties seem to be conserved across phyla $(7,13,14)$, the role of sAC in sperm exposed to aquatic habitats low in $\mathrm{HCO}_{3}{ }^{-}(2-4 \mathrm{mM})$ is enigmatic.

Here, we show that $\mathrm{sAC}$ from sea urchin and fish is directly activated at alkaline $\mathrm{pH}$ but not by $\mathrm{HCO}_{3}{ }^{-}$and $\mathrm{Ca}^{2+}$, connecting cAMP synthesis directly with $\mathrm{pH}_{\mathrm{i}}$ homeostasis. We define the role of sAC and cAMP for motility activation and chemotactic signaling. Substitutions of two amino-acid residues in the $\mathrm{HCO}_{3}{ }^{-}$-binding site of mammalian sAC, which predicts the switch from $\mathrm{HCO}_{3}{ }^{-}$to $\mathrm{pH}$ regulation, are conserved across ten phyla, suggesting that the $\mathrm{pH}$ regulation is conserved across non-mammalian sperm.

\section{Results}

\section{Mammalian and non-mammalian sAC differ in two key amino acids}

The crystal structure of the human sAC catalytic core (sAC-cat) revealed key amino acids involved in binding of $\mathrm{HCO}_{3}{ }^{-}$and ATP/ion substrates (15-18). In non-mammalian sAC, most of these residues are conserved (Supplementary Table 1) except for positively charged R176 and $\mathrm{K} 95$ that coordinate the $\mathrm{HCO}_{3}{ }^{-}$anion. In 15 out of 17 marine invertebrates examined, R176 is replaced by Asn, Ser, or Thr, while K95 is conserved (Supplementary Table 2). In both bony and cartilaginous fish (again, with one exception, Coelacanthiformes $L$.

chalumnae), K95 is replaced by Asn or Thr, while R176 is conserved (Supplementary Table 
2). Thus, the sAC of most aquatic animals lacks either one of these two key amino-acid residues that endow mammalian $\mathrm{sAC}$ with $\mathrm{HCO}_{3}{ }^{-}$sensitivity.

We studied the structural consequences in a homology model of the catalytic core of the $s \mathrm{AC}$ from A. punctulata (ApsAC-cat), consisting of two catalytic domains C1 (residues 65-229) and C2 (residues 338-542). Sequence comparison revealed that the cyanobacterial sAC homologue CyaC (PDB ID 1WCO (19)) and C2 from human sAC (PDP ID 4CLL (15)) display the highest sequence similarity to ApsAC-cat $\mathrm{C} 1$ and $\mathrm{C} 2$, respectively. Use of these two templates yielded an excellent homology model for ApsAC-cat (Fig. 1A) with proper positioning of the conserved catalytic residues (15). $\mathrm{K} 117$ is positioned toward $\mathrm{HCO}_{3}{ }^{-}$in the regulatory site of ApsAC, similar to K95 in human sAC (Fig. 1B). The smaller N198, which corresponds to human $\mathrm{R} 176$, is also oriented toward $\mathrm{HCO}_{3}{ }^{-}$; however, $\mathrm{N} 198$ remains more distant due to its shorter sidechain and a conserved main-chain fold in this region. Interestingly, the shorter sidechain results in an opening that renders the regulatory site accessible via a channel from the protein surface (Fig. 1C). In human sAC, R176 blocks this channel and access to the regulatory site is solely provided by a channel that branches off the active site. This analysis suggests that non-mammalian sAC activity may not rely on $\mathrm{HCO}_{3}{ }^{-}$.

\section{The sAC of sea urchin and salmon is regulated by $\mathrm{pH}$ but not $\mathrm{HCO}_{3}{ }^{-}$and $\mathrm{Ca}^{2+}$}

We chose sAC orthologues from A. punctulata (ApsAC) and salmon S. salar (SssAC) to study the functional consequences of R176N and K95N substitutions. Mammalian sAC, e.g., from rat $(R n s A C)$, exists as full-length $(\mathrm{fl})$ and truncated $(\mathrm{t})$ isoforms $\left(\mathrm{sAC}_{\mathrm{fl}}, 180 \mathrm{kDa}\right.$ and $\mathrm{sAC}_{\mathrm{t}}, 55$ $\mathrm{kDa}$, respectively) $(20,21)$. The specific activity of $\mathrm{sAC}_{\mathrm{t}}$ is much greater than that of $\mathrm{sAC}_{\mathrm{fl}}$ due to an autoinhibitory domain C-terminal to the C2 catalytic domain (22) that is conserved in mammalian and non-mammalian sACs. A. punctulata sperm contain only $\operatorname{sAC}_{\mathrm{fl}}(7,9)$. To allow for direct comparison with rat $R n \mathrm{sAC}_{\mathrm{t}}$, we studied artificially truncated $A p \mathrm{sAC}$ and 
SssAC. ApsAC, SssAC, and RnsAC were heterologously expressed in HEK293 cells, and cAMP synthesis was determined by ELISA.

Because $\left[\mathrm{HCO}_{3}^{-}\right]$in water is low compared to tissue levels, we stimulated sAC at various $\left[\mathrm{HCO}_{3}{ }^{-}\right]$. Unlike mammalian sAC, the activity of $A p s \mathrm{AC}_{\mathrm{t}}$ and $A p s \mathrm{AC}_{\mathrm{fl}}$ was not or only weakly affected by $\left[\mathrm{HCO}_{3}{ }^{-}\right]$at both neutral and alkaline pH (Fig. 2A, B). Moreover, cAMP synthesis of $A p s \mathrm{AC}_{\mathrm{t}}$ (MgATP as substrate) was not significantly affected by $\left[\mathrm{Ca}^{2+}\right]$ Fig. $\left.2 \mathrm{C}\right)$.

We presumed instead that alkalization, a key step in chemotactic signaling of A.punctulata sperm $(10,23,24)$, regulates sAC activity. Indeed, both truncated and full-length ApsAC isoforms were exquisitely pH-sensitive (Fig. 2D); cAMP levels rose almost 10-fold when increasing the $\mathrm{pH}$ from 7 to 8 (Fig. 2E). In the freshwater spawner salmon Salmo salar, the SssAC regulation was similar: alkaline $\mathrm{pH}$ but not $\mathrm{HCO}_{3}{ }^{-}$stimulated both $S s s \mathrm{AC}_{\mathrm{fl}}$ and $S s s \mathrm{AC}_{\mathrm{t}}$ activities (Fig. 2F).

In conclusion, the sAC from A. punctulata and $S$. salar is regulated by $\mathrm{pH}$ rather than $\mathrm{HCO}_{3}{ }^{-}$. Of note, other characteristic features such as membrane association, $\mathrm{Mn}^{2+}$ sensitivity, and higher catalytic activity of the truncated versus full-length form are shared by $\mathrm{pH}$ - and $\mathrm{HCO}_{3}{ }^{-}-$ sensitive sACs (Fig. 2; Supplementary Fig. 1).

Residues $\mathrm{R} 176$ and $\mathrm{K} 95$ endow human sAC with $\mathrm{HCO}_{3}{ }^{-}$sensitivity and are also involved in catalytic activity; replacement of both residues by alanine almost completely abolishes sAC activity (15). We tested whether $\mathrm{HCO}_{3}{ }^{-}$sensitivity of $A$. punctulata and $S$. salar sACs can be recovered by replacing N198 (the R176 position) with $\mathrm{Arg}$ in $A p \mathrm{AC}_{\mathrm{fl}}$ or N98 (the K95 position) with Lys in $S s s \mathrm{AC}_{\mathrm{fl}}$ (Fig. 2A, F). Both ApsAC and Sss AC mutants lost their pH regulation and $\mathrm{Mn}^{2+}$ sensitivity, but because they also lost most of their catalytic activity, it is unclear whether $\mathrm{HCO}_{3}{ }^{-}$regulation was restored. In conclusion, the two residues are key to sAC activation in $\mathrm{pH}-$ and $\mathrm{HCO}_{3}{ }^{-}$-regulated sACs. 


\section{A new cross-species SAC inhibitor}

Small-molecule screens identified the mammalian sAC inhibitor LRE1 $(17,25)$. We found that the LRE1 congener TDI-8164 (Fig. 3A) inhibited pH-sensitive $A p s \mathrm{AC}_{\mathrm{t}}$ as well as $\mathrm{HCO}_{3}^{-}-$ sensitive $R n s \mathrm{sC}_{\mathrm{t}}$ and human $H s \mathrm{sAC}$ with similar potency: the $\mathrm{IC}_{50}$ of $\mathrm{TDI}-8164$ to inhibit $A p s \mathrm{AC}_{\mathrm{t}}, R n s \mathrm{AC}_{\mathrm{t}}$, and human $H s \mathrm{~s} \mathrm{AC}_{\mathrm{t}}$ was $0.6 \pm 0.1 \mu \mathrm{M}, 1.6 \pm 0.36 \mu \mathrm{M}$, and $0.95 \pm 0.1 \mu \mathrm{M}$, respectively (mean \pm s.d., $\mathrm{n}=3$ ) (Fig. $3 \mathrm{C}$-E). Of note, in intact cells, the $\mathrm{IC}_{50}$ to inhibit $R n \mathrm{sAC}_{\mathrm{t}}$ was $0.51 \pm 0.08 \mu \mathrm{M}(\mathrm{Fig} .3 \mathrm{~F})$, demonstrating that TDI-8164 readily permeates cell membranes.

Although two key residues in the $\mathrm{HCO}_{3}{ }^{-}$-binding site are altered in ApsAC, the overall structure of the site remains mostly conserved (Fig. 1). Indeed, TDI-8164 fits well in the ApsAC regulatory site based on a sAC-cat/LRE1 crystal structure (17) (Fig. 3B). The shared 2-amino-4-chloro moiety occupies the mammalian SAC bicarbonate site and interacts with conserved residues such as ApsAC-K117 and L124, and the five-membered ring of TDI-8164 overlays with the LRE1 cyclopropyl group. The largest difference between the compounds is where the TDI-8164 six-membered ring and iso-butylester partly occupies the pocket accommodating LRE1's thiophene group, but then extends further toward the active site.

Contacts here include residues differing from mammalian sAC, such as ApsAC-K202 (replacing N180), which likely explains why TDI-8164 showed high potency toward ApsAC (Fig. 3B). In conclusion, TDI-8164 allows studying ApsAC and other non-mammalian sAC orthologs in intact cells of species for which gene targeting is not available.

\section{cAMP synthesis in $A$. punctulata sperm is controlled by $\mathrm{pH}$ but not $\mathrm{HCO}_{3}^{-}$}

Considering that native sAC may adopt properties different from those in vitro, we examined the regulation of cAMP synthesis in intact motile A. punctulata sperm. Of note, in sea urchin sperm, tmAC isoforms are neither detectable at the protein level (9) see however $(7,13)$ nor functional level (Supplementary Information and Supplementary Fig. 2), whereas sAC is 
highly abundant (cytosolic concentration $=6.7 \mu \mathrm{M})(9)$. Consequently, cAMP synthesis in $A$. punctulata sperm is predominantly, if not exclusively, mediated by sAC $(7,26)$ simplifying its functional characterization in sperm.

We used quenched-flow technique $(27,28)$ to determine the change in cAMP content of sperm evoked by rapid mixing with artificial sea water (ASW, pH 7.8) containing $\mathrm{HCO}_{3}^{-}$ (30 mM) or the chemoattractant peptide resact. Mixing with $\mathrm{HCO}_{3}{ }^{-}$did not elevate cAMP levels, not even in sperm that had been preincubated with IBMX, a broadly-specific inhibitor of phosphodiesterases (PDE) that prevents breakdown of cAMP (Fig. 4A). By contrast, mixing with resact resulted in a transient cAMP increase $(28,29)$ that was greatly augmented by $\operatorname{IBMX}$ (Fig. 4A, B).

Resact evokes a rapid hyperpolarization $(30,31)$ that alkalizes sperm via activation of a voltage-gated $\mathrm{Na}^{+} / \mathrm{H}^{+}$exchanger (sNHE) $(10,24,32)$. The resact-evoked hyperpolarization, alkalization, and rise of cAMP are abolished by high external $\left[\mathrm{K}^{+}\right]_{\mathrm{o}}(30 \mathrm{mM})(23,24,29,33)$, suggesting that cAMP synthesis is stimulated by the change in voltage and/or $\mathrm{pH}_{\mathrm{i}}$. Because sAC is tethered to the membrane, it may sense voltage changes. To distinguish between voltage and $\mathrm{pH}_{\mathrm{i}}$ control, we studied the activity of $\mathrm{sAC}$ upon an increase in $\mathrm{pH}_{\mathrm{i}}$ established by two different procedures. A rapid shift of $\mathrm{pH}_{\mathrm{i}}$ from 7.2 to 8.1 was imposed onto sperm (" $\mathrm{pH}$ clamp") (24) using the $\mathrm{pH}_{\mathrm{i}}$ pseudo-null-point method (34) (Supplementary Figs. 3, 4). Alternatively, sperm were alkalized by rapid mixing with the weak base $\mathrm{NH}_{4} \mathrm{Cl}$. Both procedures elevated cAMP levels (Fig. 4C, D). The sAC inhibitor TDI-8164 suppressed both the alkaline- and the resact-induced cAMP increases (Fig. 4D), indicating that it is mediated by $\mathrm{sAC}$; resact-induced cAMP synthesis was also inhibited by $30 \mathrm{mM} \mathrm{K}^{+}$, which inhibits hyperpolarization and, thereby, alkalization. To conclude, the activity of recombinant and native $\mathrm{sAC}$ is directly activated by alkaline $\mathrm{pH}_{\mathrm{i}}$. Importantly, considering that the 
hyperpolarization causes alkalization, this result also unveils the long-standing mystery of voltage-sensitive cAMP synthesis in sperm (35).

The discovery that $\mathrm{pH}$ directly controls sAC provided a new starting point to study the role of cAMP in sperm of external fertilizers during spawning and chemotaxis.

\section{Sequence of signaling events during spawning}

Non-motile sperm in seminal fluid become motile after spawning $(36,37)$. Phosphorylation of axonemal proteins by cAMP-stimulated PKA or activation of motor proteins by alkaline $\mathrm{pH}_{\mathrm{i}}$ have been proposed to activate motility $(38,39)$. Considering that $\mathrm{pH}_{\mathrm{i}}$ and $\mathrm{cAMP}$ are linked via the $\mathrm{pH}$-sensitive $\mathrm{sAC}$, we reasoned that the transition from the seminal fluid (SF) to sea water alkalizes sperm and raises cAMP levels. The ion concentrations of SF from $A$. punctulata (Supplementary Table 3) or other sea urchin species (40) are almost identical to that of sea water, except for $\mathrm{K}^{+}$and $\mathrm{pH}$. The $\left[\mathrm{K}^{+}\right]_{\mathrm{SF}}$ was $25.7 \pm 2.1 \mathrm{mM}(\mathrm{n}=5)$ vs. $9 \mathrm{mM}$ in sea water, i.e., ASW. The $\mathrm{pH}$ of undiluted freshly spawned semen (i.e., sperm + seminal fluid) and seminal fluid $\left(\mathrm{pH}_{\mathrm{SF}}\right)$, was $6.8 \pm 0.2(\mathrm{n}=5)$ vs. 7.8 of ASW. We determined the sperm $\mathrm{pH}_{\mathrm{i}}$ in artificial seminal fluid (ASF, which is ASW containing $27 \mathrm{mM} \mathrm{K}^{+}$at $\mathrm{pH}$ 6.7) using the $\mathrm{pH}$-clamp technique. The mean $\mathrm{pH}_{\mathrm{i}}$ of sperm diluted in ASF and ASW was $6.84 \pm$ $0.02(\mathrm{n}=3)$ (Supplementary Fig. 4) and 7.2 (Supplementary Fig. 5) (24), respectively. Thus, sperm alkalize after spawning.

To reveal the sequence of cellular events and the underlying mechanisms, we emulated spawning of A. punctulata sperm using rapid mixing techniques (27), while following the changes in $\mathrm{V}_{\mathrm{m}}$ and $\mathrm{pH}_{\mathrm{i}}$ using fluorescent indicators. Before mixing, sperm in ASF were loaded with the respective fluorescent probes and then diluted with ASF. The dilute sperm suspension was rapidly mixed 1:2 in the stopped-flow device with $\mathrm{K}^{+}$-free ASW (0KASW, $\mathrm{pH}$ 8.0); thus, upon mixing, $\left[\mathrm{K}^{+}\right]$dropped to $10 \mathrm{mM}$. As control, sperm were mixed with 
ASW containing $30 \mathrm{mM} \mathrm{K}{ }^{+}$(30KASW, pH 8.0), leaving $\left[\mathrm{K}^{+}\right]$unchanged. For both mixing protocols, $\mathrm{pH}_{\mathrm{o}}$ was stepped from 6.7 to 7.7 .

The $\left[\mathrm{K}^{+}\right]_{\mathrm{o}}$ controls the resting $\mathrm{V}_{\mathrm{m}}$ of sea urchin sperm (31); therefore, sperm are predicted to hyperpolarize during spawning due to the lower $\left[\mathrm{K}^{+}\right]$of ASW. Indeed, mixing with 0KASW, evoked a rapid transient hyperpolarization (Fig. 5A). The hyperpolarization was accompanied by a pronounced intracellular alkalization (Fig. 5B). Both, hyperpolarization and alkalization were completely abolished by mixing with 30KASW (Figs. 5A, B). This observation is remarkable as it shows that protons do not passively redistribute across the sperm membrane by conventional $\mathrm{Na}^{+} / \mathrm{H}^{+}$exchange. Instead, a change in $\mathrm{V}_{\mathrm{m}}$ is required, which activates the voltage-gated $\mathrm{Na}^{+} / \mathrm{H}^{+}$exchanger SLC9C1 $(9,10)$. Next, we examined whether the changes in $\mathrm{V}_{\mathrm{m}}$ and $\mathrm{pH}_{\mathrm{i}}$ during spawning affect the voltage- and $\mathrm{pH}$-gated $\mathrm{Ca}^{2+}$ channel CatSper (24). On mixing with ASW, after some latency, $\left[\mathrm{Ca}^{2+}\right]_{\mathrm{i}}$ rose continuously and reached a plateau after $90 \mathrm{~s}$ (Fig. 5C). Finally, we followed the changes in cAMP level after mixing with ASW. The resting cAMP level of sperm in ASF was extremely low $\left(3.3 \pm 1.5 \mathrm{pmol} / 10^{8}\right.$ cells, $\left.\mathrm{n}=2\right)$ and rose about 5-fold ( $15.1 \pm 4.0 \mathrm{pmol} / 10^{8}$ cells $)$ with a half-time of approximately $50 \mathrm{~s}$ after dilution into ASW (Fig. 5G). In conclusion, spawning first triggers a change in $\mathrm{V}_{\mathrm{m}}$, followed by a rise of $\mathrm{pH}_{\mathrm{i}}$ and finally a stark rise of cAMP and $\left[\mathrm{Ca}^{2+}\right]_{\mathrm{i}}$.

\section{Sperm motility is initiated by alkalization and a rise of cAMP}

Next, we examined how changes in extracellular $\left[\mathrm{K}^{+}\right]$and $\mathrm{pH}_{\mathrm{i}}$ during spawning affect motility. Upon dilution of dry sperm into ASW (1:200), $87.5 \pm 5.3 \%(\mathrm{n}=3,740$ cells) of sperm became motile, whereas dilution into ASF did not activate motility, demonstrating that the ion composition of SF rather than an unknown inhibitory factor keeps sperm quiescent. Motility activation was not instantaneous but started after about $40 \mathrm{~s}$ (Fig. 5G). After dilution into ASF at $\mathrm{pH} 7.8$, or in $\mathrm{ASW}$ at $\mathrm{pH} 6.7$, or in ASW containing $30 \mathrm{mM} \mathrm{K} \mathrm{K}^{+}(30 \mathrm{KASW})$ only about $4-15 \%$ of sperm became motile (ASW 6.7: $9.9 \pm 4.1 \%$; 30 KASW: $17.6 \pm 14.8 \%$; 
$(n=3) 490-536$ cells). These results show that the $\mathrm{pH}_{\mathrm{o}}$ difference between SF and ASW is not sufficient to initiate sperm motility and a decrease of $\left[\mathrm{K}^{+}\right]_{\mathrm{o}}$ is required. Thus, sperm motility and cAMP synthesis by sAC are triggered by the same mechanisms.

We tested whether initiation of motility also requires cAMP in salmon sperm, which become motile upon dilution into freshwater. Immotile salmon sperm bathed in salmon ASF and loaded with DEACM-caged cAMP became motile in a dose-dependent fashion upon UVuncaging cAMP (Fig. 5H, I, Supplementary Movie 1). At high cAMP concentrations, the latency of the motor response was as short as $100 \mathrm{~ms}$. Of note, because a $\mathrm{pH}_{\mathrm{i}}$ change was bypassed, a cAMP rise is sufficient to initiate motility. After the cAMP rise, sperm swam for about $20 \mathrm{~s}$ on curvilinear trajectories (Fig. 5J) until they became immotile again (Fig. 5H), reminiscent of the transient spawning-evoked motility of sperm from several other fish species (36). Our results reveal that external fertilizers share a common mechanism of motility initiation that involves a $\mathrm{pH}$-induced rise of cAMP.

\section{The chemotactic signaling pathway matures after spawning}

The relatively slow cellular events after spawning (Figs. 5A-C) may represent a maturation process reminiscent of capacitation of mammalian sperm inside the female reproductive tract (2). We probed the chemotactic cGMP-signaling pathway (9) in time using caged cGMP as a photo-trigger. Two key events - hyperpolarization and $\mathrm{Ca}^{2+}$ response - were probed by brief light flashes that released intracellular cGMP in sperm loaded with caged cGMP. Flashes were delivered $300 \mathrm{~ms}$ to $120 \mathrm{~s}$ after dilution into ASW (Fig. 5D). This stimulation protocol monitored the recruitment of signaling components. The amplitude and time course of the cGMP-evoked $\mathrm{V}_{\mathrm{m}}$ responses did not change with time after dilution, except that $\mathrm{V}_{\mathrm{m}}$ responses evoked during the first $10 \mathrm{~s}$ recovered more slowly (Fig. 5E). Thus, the cGMP-gated CNGK channel is almost instantaneously functional after dilution/spawning. By contrast, at times 
$\lesssim 20$ s after mixing, cGMP evoked no or very small $\mathrm{Ca}^{2+}$ responses whose amplitude grew with time and reached a maximum after about $90 \mathrm{~s}$ (Fig. 5D, F). The slow increase of basal $\left[\mathrm{Ca}^{2+}\right]_{\mathrm{i}}$ after mixing matched the increase of the cGMP-evoked $\mathrm{Ca}^{2+}$ responses (Fig. 5C, F). In conclusion, after spawning, CatSper channels are quiescent and require some time to become functional. The exquisite $\mathrm{pH}$ sensitivity of sea urchin CatSper (24) suggests that spawning shifts $\mathrm{pH}_{\mathrm{i}}$ to a regime where voltage-dependent activation of CatSper channels is enabled. However, the rise of $\mathrm{pH}_{\mathrm{i}}$ after mixing is almost complete within $10 \mathrm{~s}$, whereas full recruitment of functional CatSper channels requires approximately 90 s (Fig. 5G). Therefore, mechanisms in addition to a $\mathrm{pH}_{\mathrm{i}}$ shift may contribute to full CatSper functionality.

\section{cAMP promotes full recovery from hyperpolarization and the $\mathrm{Ca}^{2+}$ response}

The hyperpolarization-activated and cyclic nucleotide-gated ( $\mathrm{HCN})$ channel carries an inward $\mathrm{Na}^{+}$current that ultimately terminates chemoattractant-induced hyperpolarization $(9,12)$. During recovery from hyperpolarization, CatSper channels open and $\mathrm{Ca}^{2+}$ flows into the flagellum $(24,31)$. While hyperpolarization activates HCN channels, cAMP greatly enhances the open probability (12). We examined whether cAMP synthesis by sAC is required for HCN function by recording $\mathrm{V}_{\mathrm{m}}$ responses in the presence of the $\mathrm{sAC}$ inhibitor TDI-8164. The compound did not affect the kinetics of the resact-induced hyperpolarization, showing that cAMP is not required for activation of the pathway (Fig. 6A). By contrast, recovery from hyperpolarization was incomplete and markedly delayed by TDI-8164 (Fig. 6A). At stronger stimulation, recovery accelerated; the acceleration was prevented in the presence of TDI-8164 (Fig. 6B). Slow and incomplete recovery should affect the $\mathrm{Ca}^{2+}$ response. Indeed, at low resact concentrations, the resact-evoked $\mathrm{Ca}^{2+}$ response is abolished by TDI-8164, and at high resact concentrations, the $\mathrm{Ca}^{2+}$ response is drastically delayed and sluggish (Fig. 6C, D). As a control, TDI-8164 did not inhibit alkalization that is important for CatSper activation

(Fig. 6E, F); instead, the $\mathrm{pH}_{\mathrm{i}}$ signals in the presence of TDI-8164 were slightly larger than 
those of the control (Fig. 6E, F). In conclusion, cAMP is required for quick and complete $V_{m}$ recovery and, thereby, shapes the chemotactic $\mathrm{Ca}^{2+}$ response.

\section{Discussion}

Here, we show that metazoan sAC orthologs fall into two functionally distinct subfamilies. The original sAC family first described in mammalian sperm is directly activated by $\mathrm{HCO}_{3}{ }^{-}$ and is not $\mathrm{pH}$ sensitive. The new sAC subfamily identified here is activated by alkaline $\mathrm{pH}$ and is not sensitive to $\mathrm{HCO}_{3}{ }^{-}$. Thus, the $\mathrm{pH}$-sensitive $\mathrm{sAC}$ serves as a direct $\mathrm{pH}_{\mathrm{i}}$ sensor. In the $\mathrm{pH}$-sensitive sAC, either $\mathrm{K} 95$ or $\mathrm{R} 176$, which are key for $\mathrm{HCO}_{3}{ }^{-}$binding and activation of mammalian sAC, is exchanged for an asparagine residue, suggesting that these substitutions are responsible for the loss of $\mathrm{HCO}_{3}{ }^{-}$sensitivity and the switch to $\mathrm{pH}$ sensitivity. The species across ten phyla using the $\mathrm{pH}_{\mathrm{i}}$-regulated $\mathrm{sAC}$ comprise a large number of external fertilizers, suggesting that internal fertilizers such as mammals employ $\mathrm{HCO}_{3}{ }^{-}$-sensitive $\mathrm{sAC}$, whereas external fertilizers that spawn into aquatic environment low in $\mathrm{HCO}_{3}{ }^{-}$carry the $\mathrm{pH}$-sensitive sAC. There are notable exceptions: reptiles fertilize internally; accordingly, some species such as lizards and snakes feature the $\mathrm{R} 176 / \mathrm{K} 95$ pair, which predicts $\mathrm{HCO}_{3}{ }^{-}$sensitivity, whereas in crocodiles this amino-acid pair is not conserved. It will be interesting to examine whether the sAC from either reptiles fall along these lines or whether fertilization mechanisms are different.

Apart from coordinating $\mathrm{HCO}_{3}{ }^{-}$, the $\mathrm{R} 176 / \mathrm{K} 95$ pair is also required for catalytic function. In the human $\mathrm{K} 95 \mathrm{~A} / \mathrm{R} 176 \mathrm{~A}$ mutant, the $\mathrm{HCO}_{3}{ }^{-}$affinity is lowered only by $2-3$-fold, yet the catalytic activity is almost completely abolished (15). In the $\mathrm{pH}$-sensitive sAC, the substituted residues at these sites contribute to $\mathrm{pH}_{\mathrm{i}}$ sensitivity. Substitutions to the mammalian genotype N98K (salmon) and N198R (sea urchin) - although unsuccessful at restoring $\mathrm{HCO}_{3}{ }^{-}$ regulation, did abolish $\mathrm{pH}$ sensitivity and catalytic activity in general. We speculate that these two residues act in concert with additional regions in the polypeptide to confer either $\mathrm{HCO}_{3}{ }^{-}$ 
or $\mathrm{pH}$ sensitivity. However, the overall structure of the regulatory $\mathrm{HCO}_{3}{ }^{-} / \mathrm{H}^{+}$site is maintained as TDI-8164, which targets this site, inhibits both $\mathrm{HCO}_{3}^{-}-$and $\mathrm{pH}$-sensitive sAC with similar potency.

The evolution of sAC is intriguing. The sAC of cyanobacteria carries K95 and R176 and is regulated by $\mathrm{HCO}_{3}{ }^{-}$and $\mathrm{Ca}^{2+}(19,41,42)$. Cyanobacteria rely on $\mathrm{CO}_{2}$ and $\mathrm{HCO}_{3}{ }^{-}$as carbon source for photosynthesis (43). They evolved several $\mathrm{CO}_{2}$-concentrating mechanisms that improve photosynthetic performance and were essential for survival when $\mathrm{CO}_{2}$ levels markedly dropped around 350 Mya (44). The products of the SbtAB operon link cAMP with carbon import: association of cAMP-liganded SbtB with the $\mathrm{Na}^{+} / \mathrm{HCO}_{3}{ }^{-}$cotransporter SbtA inhibits $\mathrm{HCO}_{3}{ }^{-}$uptake $(43,45)$. When the primordial sAC was adopted by metazoan for fertilization in the sea, with a few exceptions, either one of these two amino acid sites has been changed to allow for $\mathrm{pH}$ - rather than $\mathrm{HCO}_{3}{ }^{-}$control. Finally, the two amino-acid substitutions were restored during evolution of mammals along with bicarbonate sensitivity. Thus, the $\mathrm{HCO}_{3}{ }^{-}$-sensitive sAC probably represents an adaptation to internal fertilization in the high- $\mathrm{HCO}_{3}{ }^{-}$environment of the female reproductive organ.

The function and regulation of cAMP in non-mammalian sperm have been elusive. Here we identify several different functions along the path to fertilization (Fig. 7). First, cAMP is very low in quiescent sperm and rises after spawning. A rise of $\mathrm{cAMP}$ or $\mathrm{pH}_{\mathrm{i}}$ has been considered necessary for sperm to become motile $(38,46,47)$. The discovery of a pH-sensitive sAC reconciles these seemingly contradictory mechanisms. The $\mathrm{pH}_{\mathrm{i}}$ rise happens ahead of the cAMP increase and motility activation, arguing that alkaline-stimulated cAMP synthesis followed by PKA-mediated phosphorylation of dyneins or associated proteins $(38,48)$ initiates motility. In support of this notion, a flash-induced rise of cAMP alone almost instantaneously activated vigorous motility in salmon sperm. 
Second, the spawning-induced cAMP rise may promote CatSper maturation. Both alkalization and a transient hyperpolarization are required to open CatSper channels (24). Alkalization is mediated by the sNHE exchanger, and hyperpolarization is terminated by hyperpolarizationactivated and cyclic nucleotide-gated $(\mathrm{HCN})$ channels $(12,49)$. Both, sNHE exchanger and HCN channels are activated by hyperpolarization, and their activation is directly modulated by binding of cAMP to a cyclic nucleotide-binding domain $(10,12)$. The slow rise of $\mathrm{pH}_{\mathrm{i}}$ and cAMP after spawning shifts the voltage dependence of sNHE, HCN channels, and CatSper to the final permissive voltage range.

Third, cAMP is transiently elevated after chemoattractant stimulation (Fig. 4B) (28). The role of cAMP in the chemotactic signaling pathway has been elusive. Pharmacological inhibition of the HCN channel (9) or cAMP synthesis prevents or slows down the recovery from hyperpolarization and impairs the $\mathrm{Ca}^{2+}$ response (Fig. 6). Because activity of the heterologous HCN channel is greatly enhanced by cAMP (12), we conclude that the cAMP rise promotes recovery from hyperpolarization. Thus, electric signaling in sperm is a tug-of-war between two ion channels and two cellular messengers: cGMP opens $\mathrm{K}^{+}$channels that hyperpolarize the cell, whereas cAMP opens HCN channels that blunt hyperpolarization (Fig. 7A).

Fourth, cAMP sets the voltage range of sNHE activity (10). Now, we identify the $\mathrm{pH}-$ sensitive sAC as a new target of $\mathrm{Na}^{+} / \mathrm{H}^{+}$exchange. Thus, sNHE and sAC reciprocally control each other (Fig. 7B). The reciprocal control of sNHE and sAC may be conserved across phyla. Sperm from $\mathrm{sNHE}^{-/-}$mice lack the full-length $\mathrm{sAC}_{\mathrm{fl}}$, and are immotile, rendering males infertile $(50,51)$. However, a rise of cAMP achieved by various techniques rescues motility of $\mathrm{sNHE}^{-/-}$sperm and the infertility phenotype in vitro $(50,52,53)$, suggesting a molecular and functional interaction between sAC and sNHE (50). However, because mammalian sAC is not pH-sensitive (42) and mammalian sNHE may not facilitate $\mathrm{Na}^{+} / \mathrm{H}^{+}$exchange (10), reciprocal control must be mechanistically different. 
On a final note, most external fertilizers living in an aquatic environment are directly exposed to changes in the $\mathrm{CO}_{2} / \mathrm{HCO}_{3}{ }^{-} / \mathrm{H}^{+}$equilibrium. The increase of dissolved $\mathrm{CO}_{2}$ due to climate change can affect $\mathrm{pH}_{\mathrm{i}}$ homeostasis in two ways. The reaction of $\mathrm{CO}_{2}$ with $\mathrm{H}_{2} \mathrm{O}$ to form $\mathrm{HCO}_{3}{ }^{-}$ and $\mathrm{H}^{+}$acidifies the aquatic habitat. Moreover, $\mathrm{CO}_{2}$ readily crosses cell membranes and acidifies the cytosol. A permanent disturbance of cell $\mathrm{pH}_{\mathrm{i}}$ is expected to affect $\mathrm{sAC}$ function and, thereby, reproduction of aquatic organisms (54).

Author Contributions: H.G.K., H.H., and U.B.K. designed the project. H.H., U.B.K., R.S., and T.S. designed, performed, and analyzed quenched-and/or stopped-flow experiments. H.G.K. biochemically and functionally characterized the recombinant sACs. W.B. designed and cloned all sACs. L.A. and R.P. designed, performed, and analyzed the single-cell motility experiments. M.M., A.J. and A.S. were responsible for the identification, docking studies, and synthesis of TDI-8164. J.B. and L.R.L. developed and N.K. characterized the TDI-8164 inhibitor. C.S. performed the homology modeling. C.K. characterized the purified ApsAC proteins. U.B.K. wrote the manuscript. All authors revised the manuscript for important intellectual content and approved the manuscript.

Acknowledgments: We thank Heike Krause for preparing the manuscript and D. Fey and J. Hellmann (LANUV Kirchhundem-Albaum), and A. Nemitz (Wildlachszentrum Siegburg, Rheinischer Fischereiverband, Stiftung Wasserlauf, Wahnbachtalsperren-Verband, Wanderfischprogramm NRW) for providing salmon sperm. Financial support by the Deutsche Forschungsgemeinschaft via the priority program SPP1726 "Microswimmers" (to U.B.K.) and STE1701/11 (to C.S.), from the United States National Institutes of Health R01 HD088571 and P50 HD100549 (to J.B. and L.R.L), and financial support of TDI from Takeda Pharmaceutical Company, Memorial Sloan Kettering Cancer Center, the Rockefeller University, Weill Cornell Medicine, Mr. Lewis Sonders, and other philanthropic sources, is gratefully acknowledged.

Competing Financial Interests: The authors declare no competing financial interests. 


\section{Figures}



Figure 1. Homology modeling of the soluble adenylyl cyclase sAC from A. punctulata.

(A) Overall structure of the catalytic cores $\mathrm{C} 1$ and $\mathrm{C} 2$, in rainbow coloring from $\mathrm{N}$-terminus (blue) to C-terminus (red). C1, C2 as well as the active site and the pseudo-symmetric regulatory site are indicated. (B) Regulatory site of ApsAC-cat lined by K117 (blue) and N198 (green) and overlayed with the corresponding human sAC residues binding bicarbonate (grey sticks). (C) View from the protein surface into the regulatory site of Aps AC colored according to electrostatic potential (negative red, positive blue) and overlayed with human sAC (sticks). The view shows an access channel in ApsAC that is blocked by R176 in human sAC. 

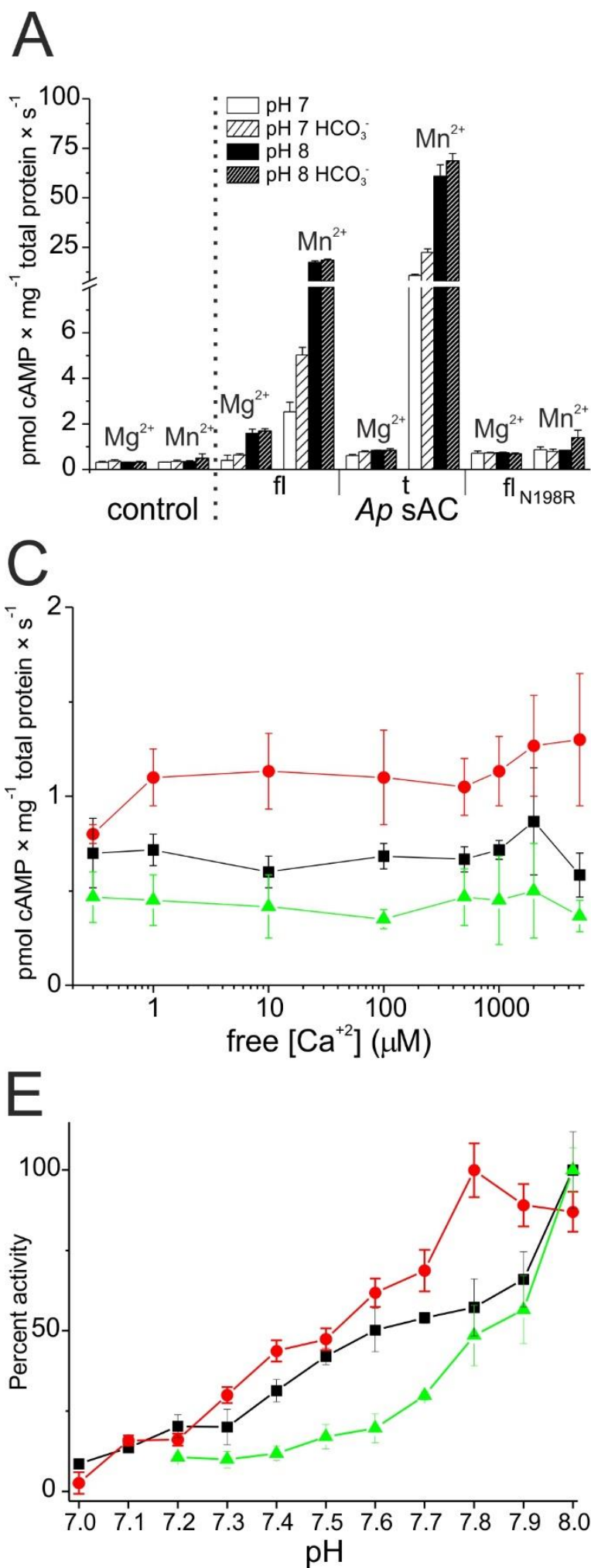

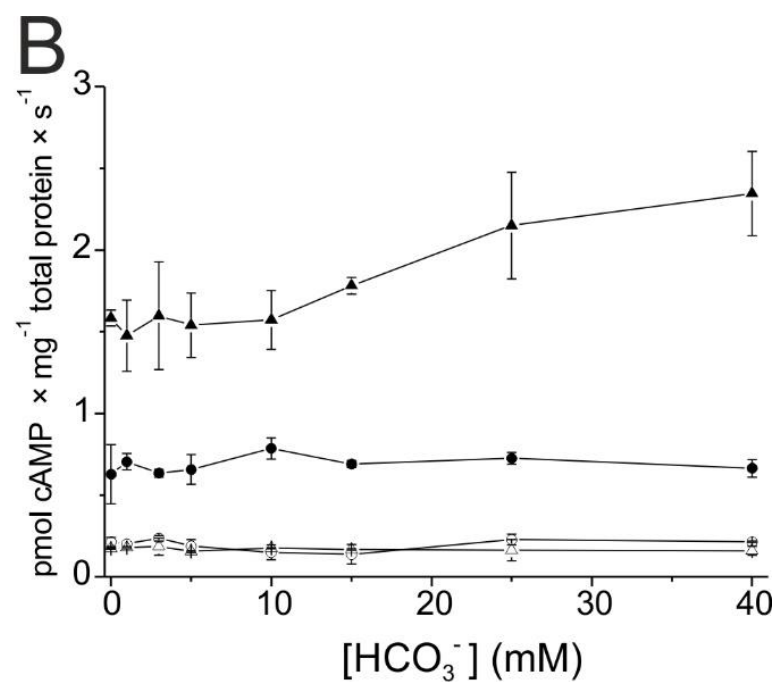

$D$
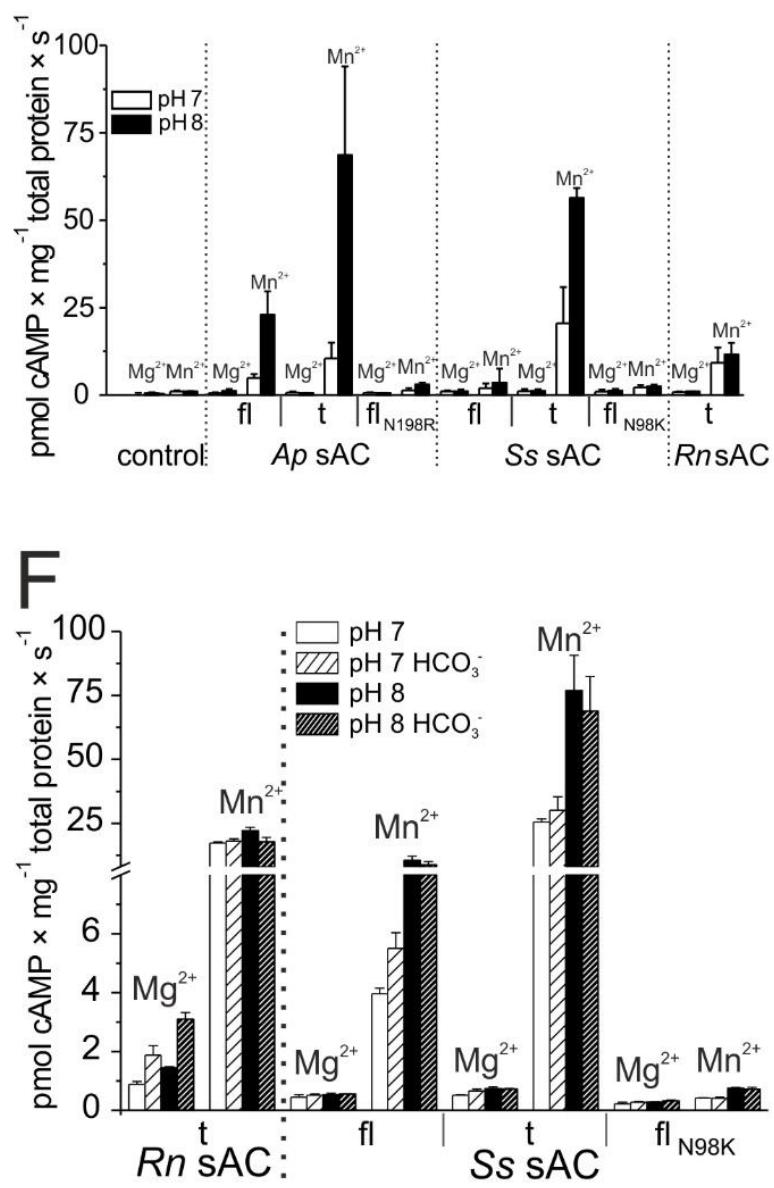

Figure 2. Heterologously expressed non-mammalian sAC orthologs are pH-sensitive and not activated by $\mathrm{HCO}_{3}{ }^{-}$and $\mathrm{Ca}^{2+}$.

(A) Bicarbonate sensitivity of heterologously expressed recombinant $\mathrm{sAC}_{\mathrm{fl}}, \mathrm{sAC}_{\mathrm{t}}$, and mutant N176R from A. punctulata at $\mathrm{pH} 7$ and 8 . MgATP $(1 \mathrm{mM})$ or MnATP $(1 \mathrm{mM})$ as substrate; 
$\mathrm{HCO}_{3}^{-} 30 \mathrm{mM}$. (B) Bicarbonate dependence of cAMP synthesis of $A p \mathrm{SAC}_{\mathrm{fl}}$ at $\mathrm{pH} 7.1(\bullet)$ and 7.7 ( $\mathbf{\Delta})$. Control cells at pH $7.1(\circ)$ and $\mathrm{pH} 7.7(\Delta)$. MgATP $1 \mathrm{mM}$. (C) $\mathrm{Ca}^{2+}$ sensitivity of sAC activity at $\mathrm{pH}=8$ of rat $\mathrm{sAC}_{\mathrm{t}}(\mathrm{red}), A p \mathrm{sCC}_{\mathrm{fl}}$ (black), and control cells (green) in the presence of $\mathrm{Mg}^{2+}(5 \mathrm{mM})$ and $\mathrm{ATP}(2 \mathrm{mM})$. (D) Activity of sAC from A. punctulata (ApsAC), S. salar (SssAC) and rat RnsAC in lysates of HEK293 cells with $\operatorname{MgATP}(1 \mathrm{mM})$ and $\operatorname{MnATP}(1 \mathrm{mM})$ at pH 7 (white) and pH 8 (black), fl, full-length; t, truncated; fl $1_{\mathrm{N} 198 \mathrm{R}}$, full-

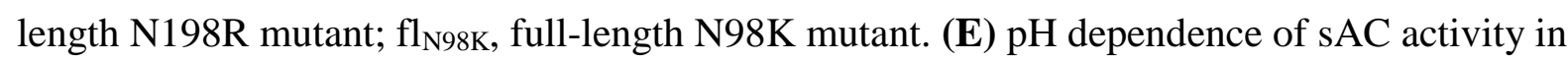
Aps AC $\mathrm{fl}_{\mathrm{fl}}$-transfected HEK cells (black), purified ApsAC $\mathrm{C}_{\mathrm{t}}$ protein (red), and A. punctulata sperm (green). (F) Bicarbonate sensitivity of heterologously expressed recombinant $\mathrm{sAC}_{\mathrm{fl}}$, $\mathrm{sAC}_{\mathrm{t}}$, and mutant $\mathrm{N} 98 \mathrm{~K}$ from the salmon $S$. salar at $\mathrm{pH} 7$ and $8 . \operatorname{MgATP}(1 \mathrm{mM})$ or MnATP $(1 \mathrm{mM})$ as substrate. 
A<smiles>CC(C)(C)OC(=O)N1CCC[C@]2(CCCN2c2cc(Cl)nc(N)n2)C1</smiles>

C

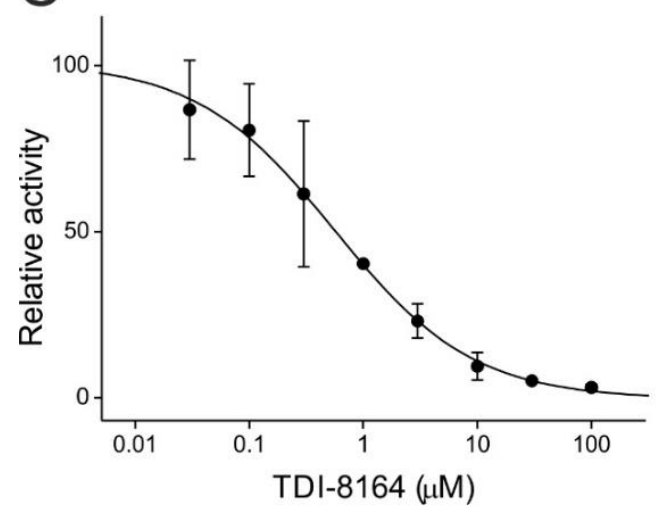

E

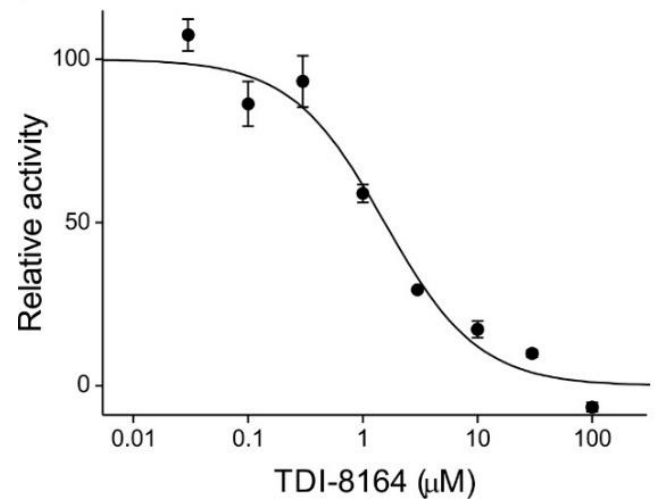

B

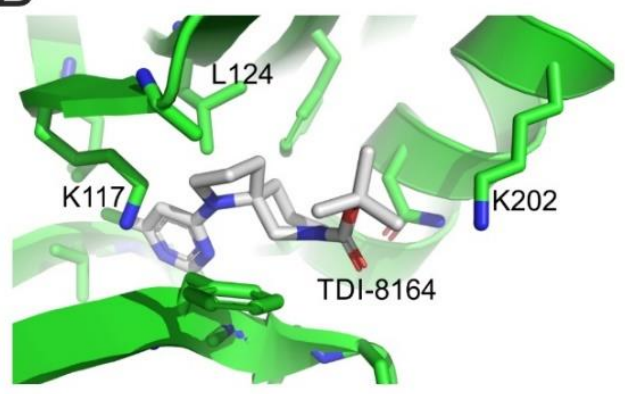

$\mathrm{D}$

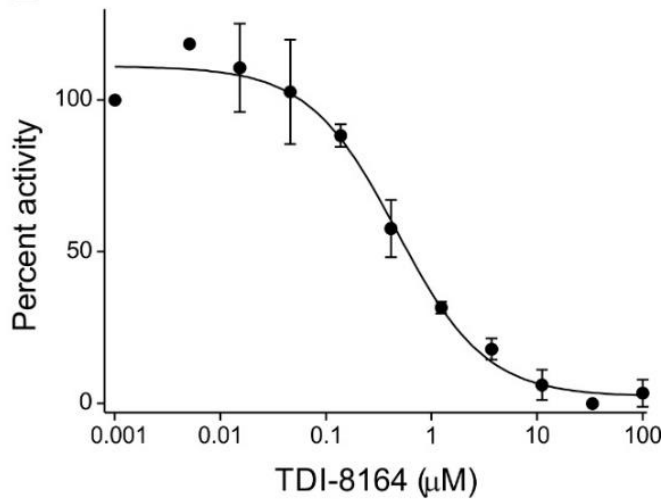

$\mathrm{F}$

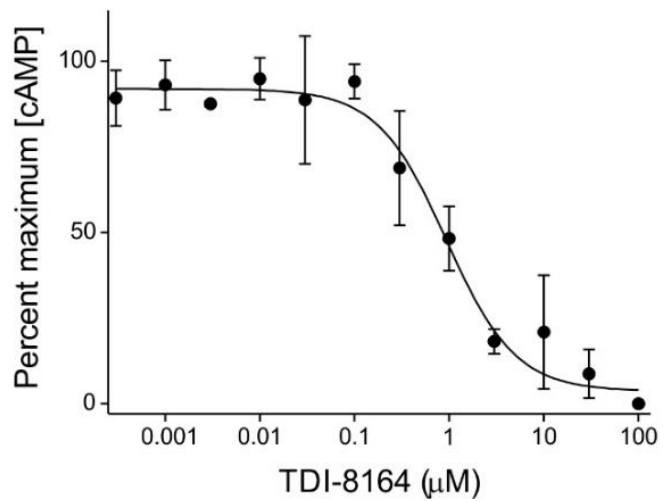

Figure 3. The drug TDI-8164 inhibits rat, human, and sea urchin sAC.

(A) Chemical structure of TDI-8164. (B) Model of the ApsAC catalytic core in complex with the inhibitor TDI-8164 (grey). Residues surrounding the compound are shown as sticks, and residues mentioned in the text are labeled. (C-F) Determination of $\mathrm{IC}_{50}$ value of cAMP synthesis for sAC inhibitor TDI-8164 using recombinant sAC from (C) sea urchin, (D) human, (E) rat in lysed HEK293 cells, and (F) rat in intact HEK293 cells. $\mathrm{Mn}^{2+}(5 \mathrm{mM})$, ATP $(1 \mathrm{mM}), \mathrm{pH}$ 7.7. The $\mathrm{IC}_{50}=0.6 \pm 0.10 \mu \mathrm{M}$ for ApsAC in lysed HEK293 cells, $1.6 \pm 0.36 \mu \mathrm{M}$ for RnsAC in lysed HEK293 cells, $0.51 \pm 0.08 \mu \mathrm{M}$ for purified HssAC protein, and $0.95 \pm$ 0.1 for RnsAC in intact HEK293 cells. Mean \pm s.d. $(\mathrm{n}=3)$ for panels $\mathrm{C}, \mathrm{E}$ and $\mathrm{n}=1-3$ for panels D, F. Solid lines represent fit of a simple binding isotherm to the data. 
A

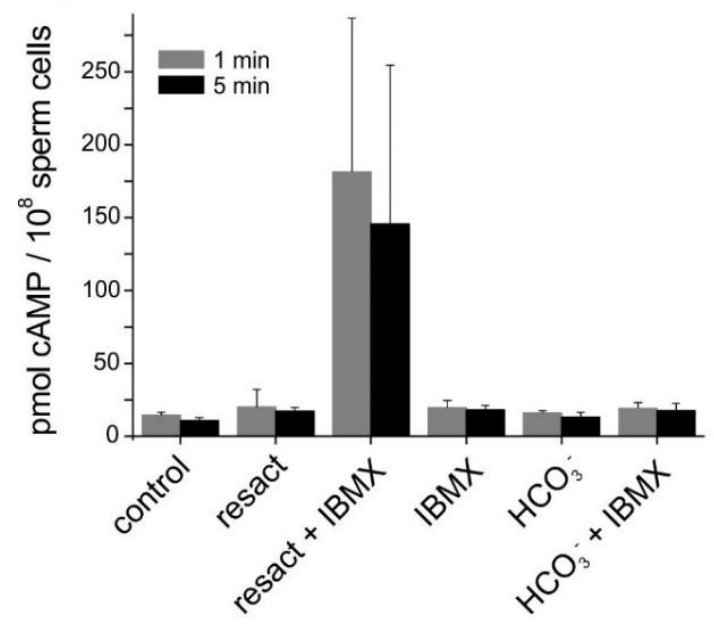

C

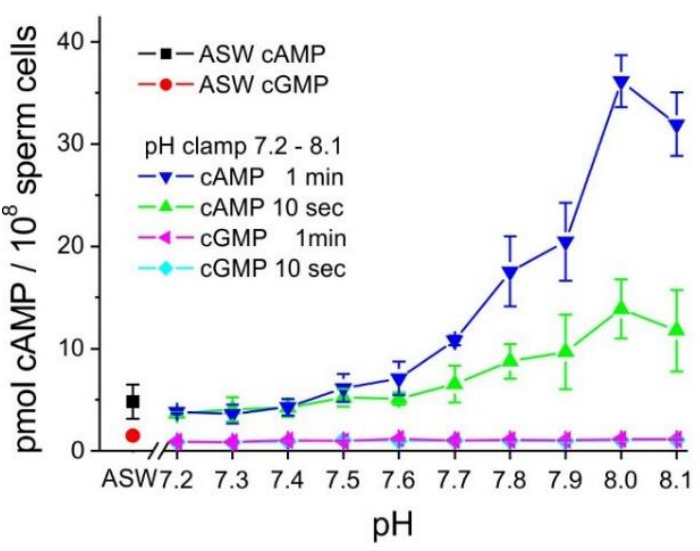

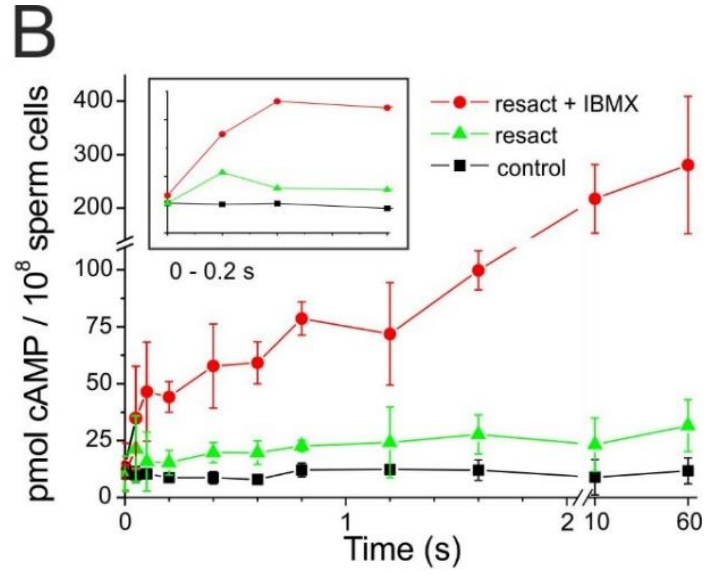
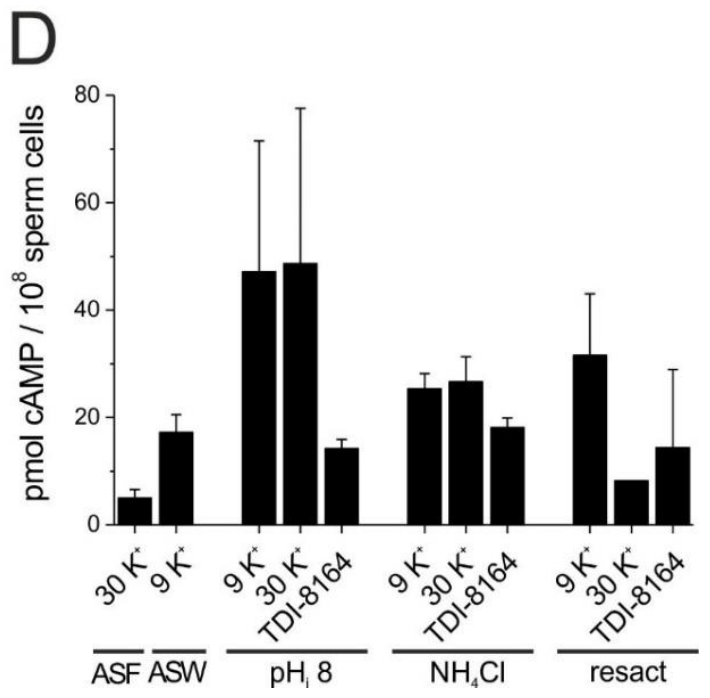

Figure 4. Control of cAMP in A. punctulata sperm.

(A) The cAMP concentrations of unstimulated control sperm and after stimulation with $\left.\mathrm{HCO}_{3}{ }^{-}(30 \mathrm{mM}), \mathrm{HCO}_{3}{ }^{-}(30 \mathrm{mM})+\mathrm{IBMX}^{-1} \mathrm{mM}\right)$, resact $(250 \mathrm{nM})$, resact + IBMX $(1 \mathrm{mM})$, and IBMX alone (1 mM) after $1 \mathrm{~min}$ (grey) and 5 min (black). (B) Time course of the changes in cAMP after rapid mixing with ASW (black), resact (250 nM, green), and resact + IBMX $(1 \mathrm{mM})$ (red). Inset: blow-up of the first $200 \mathrm{~ms} ; \mathrm{n}=3$. (C) Control of cAMP and cGMP concentrations by intracellular $\mathrm{pH}_{\mathrm{i}}$. The $\mathrm{pH}_{\mathrm{i}}$ was adjusted by the $\mathrm{pH}_{\mathrm{i}}$-clamp method. Changes in cAMP after $10 \mathrm{~s}$ (green) and $1 \mathrm{~min}$ (blue); changes in cGMP after $10 \mathrm{~s}$ (light blue) and 1 min (magenta). The control values in ASW are indicated as black (cAMP) and red (cGMP) dots; $\mathrm{n}=3$. (D) cAMP synthesis stimulated by $\mathrm{pH}_{\mathrm{i}}, \mathrm{NH}_{4} \mathrm{Cl}$, or resact and inhibited by high $\left[\mathrm{K}^{+}\right]$and the sAC inhibitor TDI-8164; $\mathrm{n}=3$, except $\mathrm{n}=1$ for resact $+30 \mathrm{mM} \mathrm{K}^{+}$. All data are the mean \pm s.d. and the indicated number $n$ of experiments. 

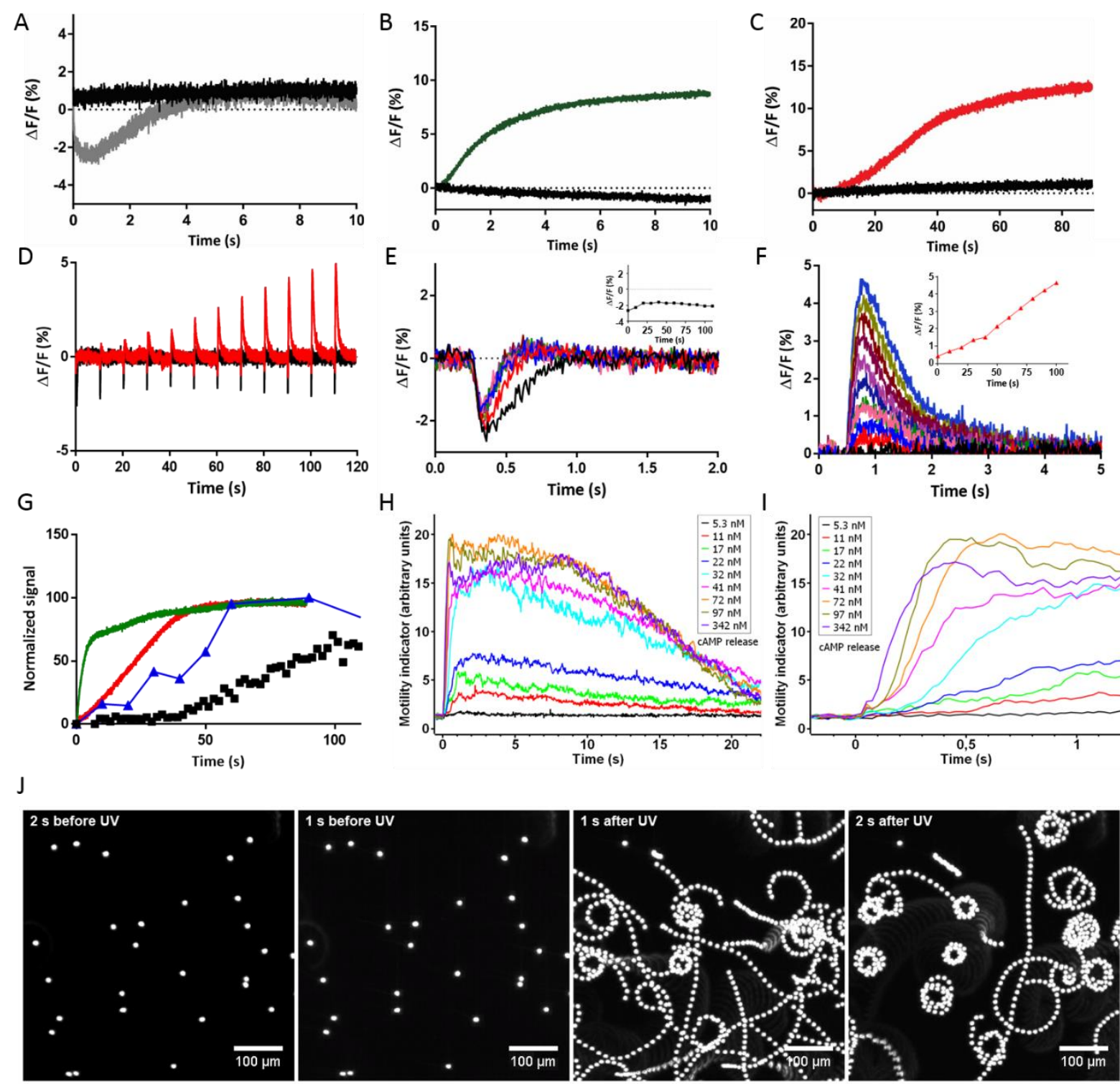

Figure 5. Cellular signaling events during spawning and activation of sperm.

(A) Changes in $\mathrm{V}_{\mathrm{m}}$ measured with the potentiometric probe FluoVolt after 1:2 mixing of sperm in ASF with 0KASW (gray) and $30 \mathrm{KASW}$ (black). (B) Changes in $\mathrm{pH}_{\mathrm{i}}$ measured with pHrodo Red after 1:2 mixing of sperm in ASF with 0KASW (red) or 30KASW (black). For comparison with $\mathrm{Ca}^{2+}$ signals, the $\mathrm{pH}_{\mathrm{i}}$ signal has been inverted. (C) Changes in $\left[\mathrm{Ca}^{2+}\right]_{\mathrm{i}}$ measured with Fluo-4 after 1:2 mixing of sperm in ASF with 0KASW (red) or 30KASW (black). (D) cGMP-evoked $\mathrm{V}_{\mathrm{m}}$ (black) and $\mathrm{Ca}^{2+}$ responses (red) after mixing sperm in ASW with OKASW. (E) Superposition of cGMP-induced $V_{m}$ responses evoked after 1:2 mixing of sperm in ASF with 0KASW; flash was applied in 10-s increments from $\mathrm{t}=300 \mathrm{~ms}$ (black) to $\mathrm{t}=110 \mathrm{~s}$ (turquoise). Inset: amplitude of $\mathrm{V}_{\mathrm{m}}$ versus time. (F) Superposition of cGMP-induced $\mathrm{Ca}^{2+}$ responses evoked by the indicated times after 1:2 mixing of sperm in ASF with OKASW color-coded as in panel E. Inset: amplitude of $\mathrm{Ca}^{2+}$ responses versus time. (G) Comparison of 
the time course of $\mathrm{pH}_{\mathrm{i}}$ response (green), $\mathrm{Ca}^{2+}$ response (red), cAMP increase (blue), and motility (black) after dilution by ASW of sperm incubated in ASF. (H) Initiation of motility by UV light flashes of different energy in salmon sperm bathed in salmon ASF and loaded with DEACM-caged cAMP $(20 \mu \mathrm{M})$, which raised cAMP concentrations from $5.3 \mathrm{nM}$ to $342 \mathrm{nM}$. Each data point represents the mean from three animals and 6-9 experiments. (I) Extended timescale that illustrates the dose-dependent latency of the motor response. UV flash was delivered at $\mathrm{t}=0$. (J) Trajectories of salmon sperm from Supplementary Video 1 recorded $1 \mathrm{~s}$ and $2 \mathrm{~s}$ before (left) and after (right) release of cAMP by light. 
A
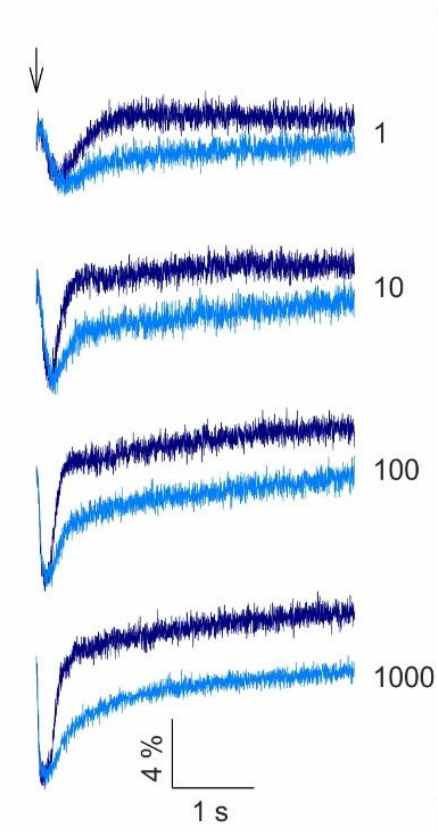

B

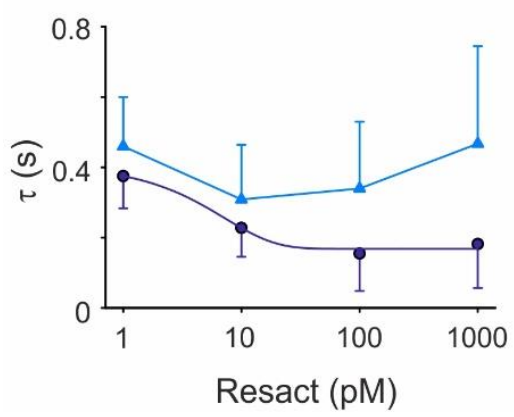

C
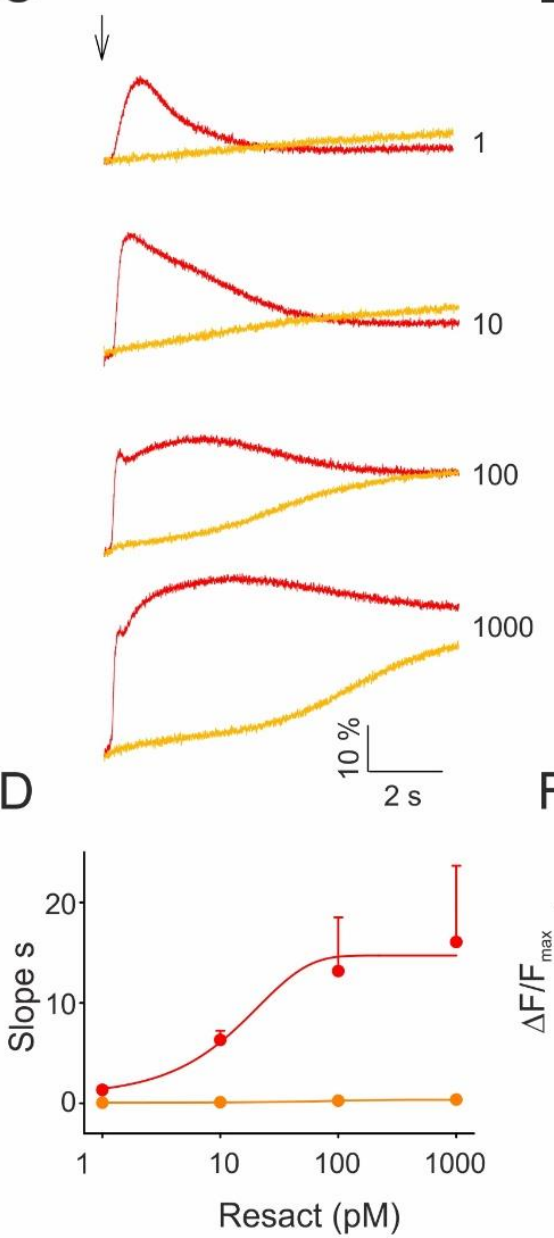

E
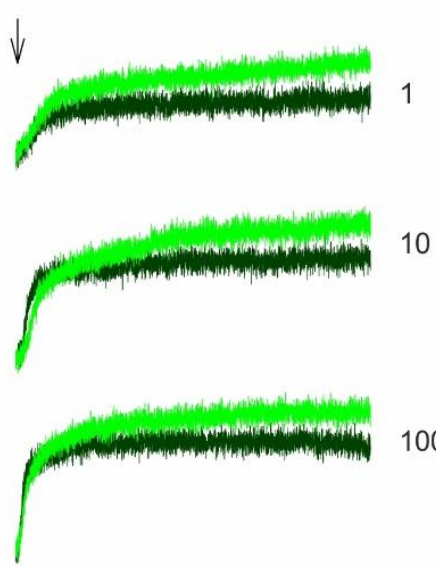

100

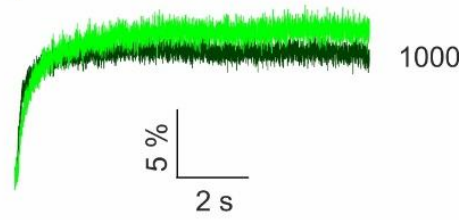

$\mathrm{F}$

0

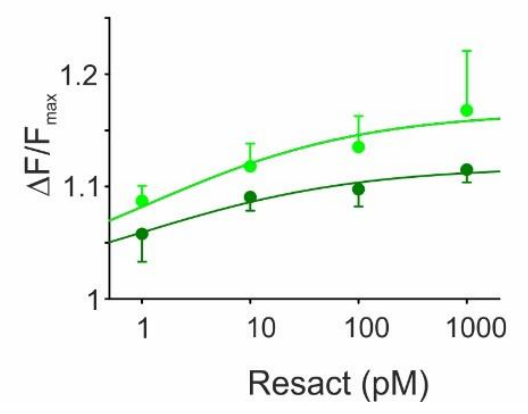

Figure 6. The sAC inhibitor TDI-8164 slows $\mathrm{V}_{m}$ recovery and impairs $\mathrm{Ca}^{2+}$ response.

(A) Resact-evoked hyperpolarization in the absence (dark blue) and presence (light blue) of TDI-8164 $(30 \mu \mathrm{M})$; resact concentrations are indicated in pM; voltage-sensitive dye Di-8ANEPPS $(2 \mu \mathrm{M})$. (B) Time constant of repolarization in control (dark blue) and TDI-8164treated (light blue) sperm. (C) Resact-evoked $\mathrm{Ca}^{2+}$ responses in control (red) and TDI-8164treated sperm (orange); resact concentrations as indicated; $\mathrm{Ca}^{2+}$ dye Fluo-4 (10 $\left.\mu \mathrm{M}\right)$. (D) Initial rate of $\mathrm{Ca}^{2+}$ increase in control (red) and TDI-8164-treated sperm (orange) in dependence on resact concentration. (E) Resact-evoked alkalization in the absence (dark green) and presence (light green) of TDI-8164 (30 $\mu \mathrm{M})$; BCECF dye $(10 \mu \mathrm{M})$. (F) Relative changes $\Delta \mathrm{F} / \mathrm{F}_{\max }$ of BCECF without (dark green) and with TDI-8164 (light green). All data are mean \pm s.d. $(n=3)$ 
A

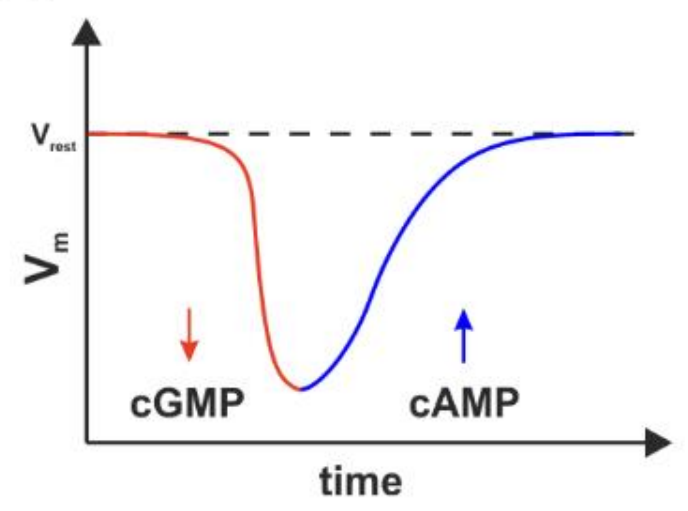

B

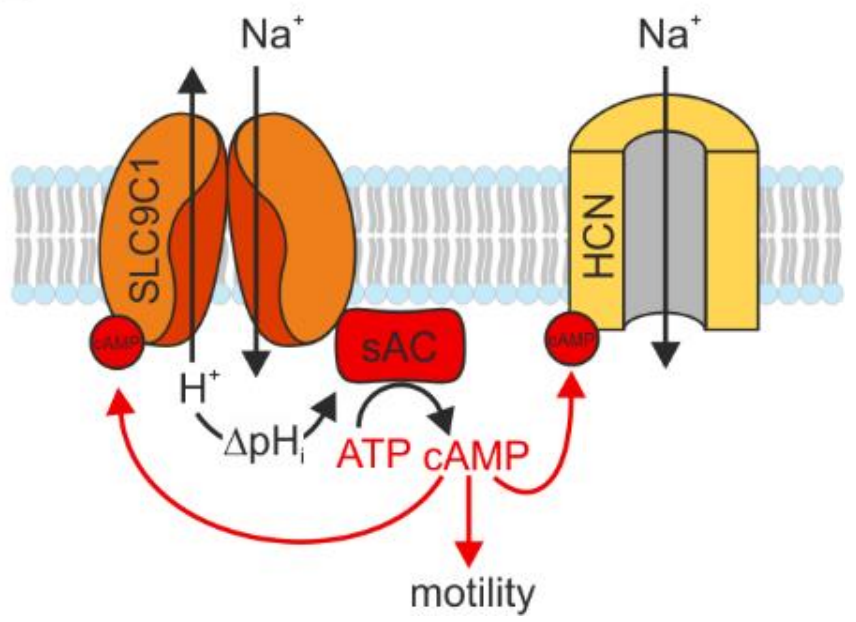

Figure 7. Model of SAC function and cAMP targets.

(A) The hyperpolarizing $\mathrm{V}_{\mathrm{m}}$ response is shaped by two ion channels and two cell messengers: cGMP opens CNGK channels that cause hyperpolarization, and cAMP opens HCN channels that cause depolarization. (B) The $\mathrm{Na}^{+} / \mathrm{H}^{+}$exchanger SLC9C1 and the sAC reciprocally control each other's activity. cAMP shifts $\mathrm{V}_{1 / 2}$ of sNHE activation, and sNHE controls sAC via $\mathrm{pH}_{\mathrm{i}}$. It enhances the open probability of $\mathrm{HCN}$ channels and, thereby, contributes to CatSper channel opening during recovery from chemoattractant-evoked hyperpolarization; finally, cAMP controls dynein motor proteins via phosphorylation. 


\section{Methods}

\section{Homology modeling of ApsAC and its TDI-8164 complex}

A homology model of Aps AC was generated with Modeller v9 (55), using the closest homologs from the PDB as templates: CyaC from S. platensis (PDB ID 1WC0) (19) for C1 and human sAC-C2 (PDB ID 4CLL) (15) for C2. A model of an ApsAC complex with the inhibitor TDI-8164 was generated by overlaying the ApsAC1 model with a hssAC-cat structure in complex with the related compound LRE1 (PDB ID 5IV4) (17). Coordinates and parameters for TDI-8164 were generated with ProDrg2 (56) and the compound was superposed on LRE1, followed by manual adjustment of the compound conformation within the binding site.

\section{Identification of TDI-8164 (tert-butyl (R)-1-(2-amino-6-chloropyrimidin-4-yl)-1,7- diazaspiro[4.5]decane-7-carboxylate)}

TDI-8164 is the sole active enantiomer of a racemic mixture originally identified as a potent sAC inhibitor that was inert against mammalian tmACs (data not shown). The parent racemic compound was derived from a high-throughput organic synthesis (HTOS) of 50 LRE1 analogs. Briefly, a library of 1000 compounds was computationally enumerated based on the 2-amino6-chloropyrimidine scaffold of LRE1 with 500 amine and 500 aldehyde building blocks provided by a CRO (Axcelead). The enumerated compounds were then computationally docked to the crystal structure of hsAC (PDB ID 5IV4) using rDock (http://rdock.sourceforge.net/), energy minimized, and re-scored by induced-fit docking energy in MOE (https://www.chemcomp.com/Products.htm). A diverse subset of 48 compounds was selected for synthesis from the top-scoring 100 compounds in each enumeration set, and evaluated by the RapidFire Mass Spec hsAC assay. 


\section{Synthesis of TDI-8164 (tert-butyl (R)-1-(2-amino-6-chloropyrimidin-4-yl)-1,7- diazaspiro[4.5]decane-7-carboxylate)}

Step 1<smiles>CC(C)(C)OC(=O)N1CCCC2(CCCN2)C1</smiles>

racemic 1

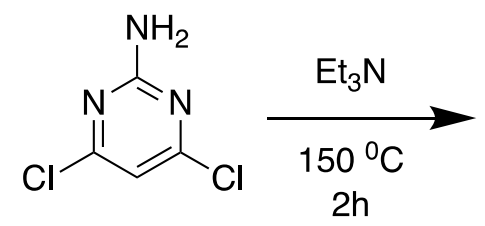

2<smiles>CC(C)(C)OC(=O)N1CCCC2(CCCN2c2cc(Cl)nc(N)n2)C1</smiles>

racemic 3

Compound 2 (1.02 g, $6.24 \mathrm{mmol}, 3$ eq), Et $3 \mathrm{~N}(630 \mathrm{mg}, 6.2 \mathrm{mmol}, 0.87 \mathrm{~mL}, 3$ eq) and racemic 1 (500 mg, $2.08 \mathrm{mmol}, 1 \mathrm{eq}$ ) were taken up into a microwave tube. The sealed tube was heated at $150^{\circ} \mathrm{C}$ for $2 \mathrm{~h}$ under microwave irradiation. The mixture was cooled to $25^{\circ} \mathrm{C}$. The reaction was repeated four times, and the resulting crude mixtures were purified by preparative-HPLC (column: Kromasil Eternity XT 250, 80mm x $10 \mathrm{~mm}$; mobile phase: [water (0.05\% ammonia hydroxide $\mathrm{v} / \mathrm{v})-\mathrm{ACN}] ; \mathrm{B} \%: 60 \%-80 \%, 33$-minute gradient) to afford racemic $3(2.30 \mathrm{~g}, 5.91 \mathrm{mmol})$ as a brown solid. LCMS $(\mathrm{M}+\mathrm{H})^{+} 368.3$.

Step 2<smiles>Nc1nc(Cl)cc(N2CCCC23CCCN(C(=O)OCc2ccccc2)C3)n1</smiles>
racemic 3<smiles>Nc1nc(Cl)cc(N2CCC[C@]23CCCN(C(=O)OCc2ccccc2)C3)n1</smiles>

$(S)-3$<smiles>CC(=O)OC(=O)N1CCC[C@]2(CCCN2c2cc(Cl)nc(N)n2)C1</smiles>

$(R)-3$ (TDI-8164)

Racemic 3 (2.30 g, $5.91 \mathrm{mmol}$ ) was purified by chiral preparative SFC (column: DAICEL CHIRALPAK AD (250 mm x $30 \mathrm{~mm}, 10 \mathrm{~mm})$; mobile phase: [0.1\% $\mathrm{NH}_{3} \mathrm{H}_{2} \mathrm{O}$ in EtOH]; $\mathrm{B} \%$ : 40\%, isocratic elution) to afford (S)-3 (Peak 1: $0.863 \mathrm{~g}, 2.30 \mathrm{mmol}, 37 \%$ yield) and $(R)-3$ (Peak 2: TDI-8164, $0.899 \mathrm{~g}, 2.43 \mathrm{mmol}, 39 \%$ yield) as yellow solids. ${ }^{1} \mathrm{H}$ NMR (400 MHz, $\left.\mathrm{CDCl}_{3}\right) \delta: 5.77(\mathrm{~s}, 1 \mathrm{H}), 4.76(\mathrm{~s}, 2 \mathrm{H}), 4.17$ - $4.03(\mathrm{~m}, 2 \mathrm{H}), 3.74$ - $3.72(\mathrm{~m}, 1 \mathrm{H}), 3.46$ - $3.37(\mathrm{~m}$, 2H), 3.22 - $3.21(\mathrm{~m}, 1 \mathrm{H}), 2.69(\mathrm{~m}, 1 \mathrm{H}), 2.21-2.18(\mathrm{~m}, 1 \mathrm{H}), 1.92(\mathrm{~s}, 2 \mathrm{H}), 1.75-1.69(\mathrm{~m}, 2 \mathrm{H})$, $1.63(\mathrm{~m}, 1 \mathrm{H}), 1.46(\mathrm{~s}, 9 \mathrm{H}), 1.41-1.38(\mathrm{~m}, 1 \mathrm{H})$. 


\section{Cloning of full-length and truncated sAC and sAC mutants}

Three sets of primer pairs, designed using genomic data of A. punctulata, were used to obtain the full-length sequence of soluble adenylate cyclase (sAC) by PCR amplification on a $A$. punctulata testis library. Primers C3299 and C3302 were used to amplify the 5' part of the sequence (bp 1 to 1790). Primer C3299 introduces a BamHI site followed by a perfect Kozak sequence preceding the start codon. Primer C3302 introduces an EcoRI site by silent mutation. Primers C3307 and C3310 were used to amplify bases 1768 to 3717 . Primer C3310 introduces a XbaI site by silent mutation. The 3' part (bp 3704 to 5556) was amplified with primers C3315 and C3318, followed by a PCR with primers C3315 and C1001, which adds a sequence for an HA-tag to the 3' end followed by a stop codon and a NotI site. The primer sequences were:

CACCGGATCCACCATGAGTGAGGCTATAAACTCAACACAG (C3299)

ACCAGAATTCTCCGATGGTCTCCTCTCTCTCGC (C3302)

GGAGACCATCGGAGAATTCTGGTGTTCCAGGG (C3307)

GCCTTCTAGAGGTTCATCATCATCTGAGGAATC (C3310)

AACCTCTAGAAGGCAGACCCAAGGAATATAAC (C3315)

TAATAAGCGGCCGCTAGGCGTAGTCGGGCACGTCGTAGGGGTATTCCTCTTCACC CCTGGGGAGAG (C3318)

\section{TAATAAGCGGCCGCTAGGCGTAGTCGGGCACGTCGTAGGGG (C1001)}

The three resulting PCR fragments were cloned into vector pcDNA6/V5-HisA (Invitrogen, Carlsbad, USA) digested with BamHI and NotI to obtain the full-length clone. The DNA for the $S$. salar sAC was synthesized according to the annotated sequence for the soluble adenylate cyclase 10, XM_014151728. A HA-tag was added to the C-terminal end. The DNA was cloned via HindIII and XbaI sites into vector pcDNA3.1/zeo(+) (Invitrogen, Carlsbad, USA). Mutations were introduced into the sequences by standard methods. 
pc6-ApsACN198R was constructed using primers C3299, C4097 and C4098, which introduces the mutation N198R, and primer C1001. The resulting PCR fragment was cloned into vector pcDNA6/V5-HisA (Invitrogen, Carlsbad, USA). The primer sequences were:

\section{CACCGGATCCACCATGAGTGAGGCTATAAACTCAACACAG (C3299)}

CAAACTTCTCGGCGATTCTAGCCTCCAGTACTG (C4097)

CAGTACTGGAGGCTAGAATCGCCGAGAAGTTTG (C4098)

\section{TAATAAGCGGCCGCTAGGCGTAGTCGGGCACGTCGTAGGGG (C1001)}

Truncated sAC from Arbacia punctulata (Met 1 to Leu 577) was constructed by successively PCRs using 5' primer C3299 and 3' primers C3680, C3681, C3682. Primer C3680 matches to the ApsAC up to L577 and adds a part of the HA-tag, primer C3681 adds part of the HA-tag, followed by a short linker (Gly, Ser, Gly), primer C3682 adds a hexa His-tag, followed by a stop codon and a XbaI site. The resulting PCR fragment was cloned into vector pcDNA6/V5HisA (Invitrogen, Carlsbad, USA). The primer sequences were:

\section{CACCGGATCCACCATGAGTGAGGCTATAAACTCAACACAG (C3299)}

GGGCACGTCGTAGGGGTACAAGAAGATAGACATCTCCTTGTCTCG (C3680)

GGTGGCCGCTGCCGGCGTAGTCGGGCACGTCGTAGGGGTACAAG (C3681)

ATATCTAGATTAGTGGTGGTGGTGGTGGTGGCCGCTGCCGGCGTAG (C3682)

pc3Z-SssACN98K was constructed using primers C3978, C4099, C4100 and primer C0609. Primer C3958 introduces a HindIII site followed by a perfect Kozak sequence preceding the start codon, Primers C4099 and C4100 introduce mutation N98K. Primer C0609 anneals to the HA tag. The resulting PCR fragment was cloned into vector pcDNA3.1/zeo(+) (Invitrogen, Carlsbad, USA). The primer sequences were:

TAAGCTTCCACCATGGGCTGGATCAAGGGCGACGGCGAGATCGAG (C3978) CGTCGCCGGCGTACTTCAGGATGTCGCC (C4099)

GGCGACATCCTGAAGTACGCCGGCGACG (C4100)

TCTTCTAGATTAGGCGTAGTCGGGCACGTCGTAGGGG (C0609) 
Truncated sAC from Salmon salar (Met 1 to Ser 499) was constructed by successively PCRs using 5' primer C3978 and 3' primers C4256, C4257, C3682. Primer C3680 matches to the ApsAC to L577 and add a part of the HA-tag, primer C3681 adds part of the HA-tag, followed by a short linker (Gly, Ser, Gly), primer C3682 adds a hexa His-tag, followed by a stop codon and a XbaI site. The resulting PCR fragment was cloned into vector pcDNA6/V5HisA (Invitrogen, Carlsbad, USA). The primer sequences were:

TAAGCTTCCACCATGGGCTGGATCAAGGGCGACGGCGAGATCGAG (C3978) GTCGGGCACGTCGTAGGGGTAGCTGTACACCTCGATCTCCTTCTCC (C4256) GTGGTGGCCGCTGCCGGCGTAGTCGGGCACGTCGTAGGGGTAGC (C4257) ATATCTAGATTAGTGGTGGTGGTGGTGGTGGCCGCTGCCGGCGTAG (C3682)

Truncated sAC from $R$. norvegicus with a HA-tag added to the C-terminal end representing the N-terminal domain (Met 1 to Val 469) of sAC (57) was cloned into pcDNA5/FRT (Invitrogen).

\section{Cloning, expression, and purification of the $A p s A_{t}$ catalytic core}

cDNA for A. punctulata sAC (aa 1-577) was subcloned into pQE70-2Z.4 (from U. Kutay, ETH Zürich), with the structure Z-Z-His6-TEV-Ap-sAC, via BamHI and HindIII sites. The solubility-enhancing Z-tag corresponds to the IgG-binding domain of S. aureus protein A (UniProt P02976, aa 158-269). E. coli M15 (Qiagen) was transformed with ApsAC (1577):pQE70-2Z.4 and grown in LB media to OD600 $\approx 0.7$. After IPTG induction $\mathrm{O} / \mathrm{N}$ at $20{ }^{\circ} \mathrm{C}$, cells were harvested, chemically lysed and the cleared lysate purified via Ni-IMAC, TEV cleavage, reverse IMAC, and gel filtration on Superdex 200. The ApsAC catalytic core corresponds to that of rat and human sAC and is very similar to the truncated alternatively splice form $\mathrm{sAC}_{\mathrm{t}}$ of mammalian $\mathrm{sAC}$. For simplicity, we refer to all catalytic-core constructs as $\mathrm{sAC}_{\mathrm{t}}$. 
The activity of purified $A p s \mathrm{CC}_{\mathrm{t}}$ protein was measured as follows. Duplicates of $100 \mu \mathrm{l}$ containing $2 \mathrm{ng} / \mu \mathrm{l}$ purified $A p \mathrm{sCC}_{\mathrm{t}}(1-577)$ were incubated at $25^{\circ} \mathrm{C}$ in a buffer containing (in mM): 100 BIS-TRIS-Propane at pH 7.0 to 8.0 in $0.1 \mathrm{pH}$ steps, $12 \mathrm{NaCl}, 120 \mathrm{KCl}, 5 \mathrm{MnCl}_{2}, 1$ $\mathrm{MgCl}_{2}, 2 \mathrm{CaCl}_{2}$ and 5 ATP. Buffer without protein at $\mathrm{pH}=7.0$ served as negative control. Aliquots $(20 \mu \mathrm{l})$ were removed at 10 -min intervals from 0 to 30 mins, quenched with $0.5 \%$ trifluoroacetic acid (TFA) and immediately shock-frozen in liquid $\mathrm{N}_{2}$. Upon assay completion, samples were thawed, spun for 5' at 14,680 rpm, and $2 \mu 1$ diluted with $100 \mu \mathrm{l}$ MPW. The diluted samples were analyzed over a Prototype XBridge BEH C18 column (2.5 $\mu \mathrm{m} \mathrm{XP}, 2.1 \times 75 \mathrm{~mm}$ ) at $30{ }^{\circ} \mathrm{C}$ with a gradient $2-100 \% \mathrm{ACN}$ in $10 \mathrm{mM} \mathrm{NH} 4 \mathrm{OAc} \mathrm{pH} 4.5$ over a 5' run on a Waters Acquity UPLC. Peaks were integrated and cAMP signals normalised to $\%$ of total area (ATP + ADP +AMP + cAMP).

\section{Cell lines}

For heterologous expression, HEK293 cells from the European Collection of Authenticated Cell Cultures (ECACC) were used. Mycoplasma tests were carried out regularly once a year. The results of the mycoplasma tests are available upon request.

\section{Generation of HEK293 cell lines stably expressing ApsAC or SssAC or RnsACt}

HEK293 cells were electroporated with plasmids using the Neon 100 Kit (Invitrogen, Carlsbad, USA) and a MicroPorator (Digital Bio) according to the manufacturer's protocol (3 $\times 1245 \mathrm{mV}$ pulses with a $10-\mathrm{ms}$ pulse width). Cells were transferred into complete medium composed of M10 plus GlutaMAX or DH10 plus GlutaMax (Invitrogen) and 10\% fetal bovine serum (Biochrom, Berlin, Germany). To select monoclonal cells stably expressing $\mathrm{sAC}$, the respective antibiotic was added to the cell culture medium $24 \mathrm{~h}$ after electroporation. Monoclonal cell lines were identified by immunocytochemistry using a rat anti-HA antibody 
(Roche Applied Science). HEK293 cells stably overexpressing rat sAC $\mathrm{t}_{\mathrm{t}}$ were as described (58).

\section{Cyclase activity assay of recombinant human $s A C_{t}$ protein}

In vitro activity of GST-tagged $H s \mathrm{sAC}_{\mathrm{t}}$ was performed as described previously (15). Briefly, activity was assayed in $100 \mu \mathrm{l}$ reactions containing (mM): $5 \mathrm{MgCl}_{2}, 5 \mathrm{CaCl}_{2}, 40 \mathrm{NaHCO}_{3}, 1$ ATP, 50 Tris $\mathrm{pH} 7.5$, and the indicated concentration of TDI-8164. Each reaction contained $\sim 1,000,000$ counts of $\alpha^{-32} \mathrm{P}$ labeled ATP. The cAMP was purified using sequential Dowex and Alumina chromatography as previously described (59).

\section{Preparation of sperm samples and flagella}

Collection of dry sperm from Arbacia punctulata was described previously (27). Briefly, 0.2$0.5 \mathrm{ml}$ of $0.5 \mathrm{M} \mathrm{KCl}$ was injected into the sea urchin cavity to induce spawning. Spawned sperm (dry sperm) were collected using a Pasteur pipette and stored on ice. Sperm from mature salmon males (Salmon salar) were provided by the Department of Fish Ecology of LANUV (State Agency for Nature, Environment, and Consumer Protection of the State of North-Rhine Westphalia) (Kirchhundem-Albaum, Germany) and the Aqua-Wild Salmon Centre (Siegburg, Germany). Briefly, mature males were anaesthetized with Tricain (MS222). Fish were rinsed and blotted clean using paper towels. Sperm samples were released by gentle abdominal pressure and collected in 100-ml PP cups with screw caps (Sarstedt, Nümbrecht, Germany) and immediately stored on ice. Stripped fish were returned to recovery tanks. Sperm density was calculated using a Neubauer counting chamber (Carl Roth; Karlsruhe, Germany). For counting, sperm cells were diluted 1:32,000 in PBS. Sperm density was $1.64 \times 10^{10} \pm 0.47 \times 10^{10}$ cells $/ \mathrm{ml}(\mathrm{n}=9)$. Preparation of sperm flagella were as described $(9)$.

\section{Western blotting}

Flagella and heads from A. punctulata sperm were prepared as described (9). Briefly, flagella were resuspended in solubilization buffer containing (mM): $140 \mathrm{NaCl}, 1$ EDTA, 10 Tris-HCl 
at $\mathrm{pH}$ 7.6, 1\% dodecyl-maltopyranoside (DDM), and protease inhibitor cocktail 1:500 (P8340, Sigma Aldrich, USA)), incubated on ice for $60 \mathrm{~min}$ and sonicated three times for $30 \mathrm{~s}$ (Sonifier 450, Branson, Danbury, CT). After incubation, supernatant and pellet were separated by centrifugation $\left(10,000 \times \mathrm{g}\right.$ at $\left.4^{\circ} \mathrm{C}\right)$. Supernatant was subjected to Western blotting. Non-transfected HEK293 (control) and HEK293 cells stably expressing HA-tagged sAC were lysed by sonification in a hypotonic buffer containing (mM): 2 Hepes/NaOH at $\mathrm{pH} 7.4,0.2$ EDTA, $10 \mathrm{NaCl}$ and 1:500 protease inhibitor mixture mPIC (Sigma Aldrich, St. Louis, USA). The suspension was subjected to Western blotting. Protein concentration was determined using the Bradford assay or the BCA test kit (Pierce) according to the manufacturer's protocol. Solubilized sperm flagella and heads from A. punctulata, hypotonically treated HEK293 cells heterologously expressing HA-tagged sAC, and HEK293 control cells were separated by SDS-PAGE using TruPAGE precast gels (4-12\%) (Sigma-Aldrich) or 8\% Laemmli SDS-gels. Samples were denatured for $10 \mathrm{~min}$ at $95{ }^{\circ} \mathrm{C}$ prior to separation. Protein Marker VI (AppliChem, Darmstadt, Germany) was used as molecular weight markers. Proteins were transferred onto an Immobilon FL PVDF membrane (Merck Millipore, Darmstadt, Germany), probed with antibodies, and analyzed using the Odyssey Imaging System (LI-COR, Bad Homburg, Germany). Figures were prepared using CorelDraw and Photo-Paint software (both from Corel Corporation). Primary antibodies were: rat-anti-HA (1:5,000; Roche Applied Science catalog, Penzberg, Germany), mouse-anti-HA (1:5,000; Sigma-Aldrich). Secondary antibodies were IRDye680 and IRDye800 antibodies (LI-COR, $1: 25,000)$.

\section{Measurement of SAC activity and quantification of cAMP content in sperm and cell}

\section{lines}

The cAMP synthesis of intact sperm from sea urchin and salmon under various salt and $\mathrm{pH}$ conditions on the sub-second time scale was analyzed using the stopped-flow instrument. 
Experiments on the seconds to minutes time scale were performed at room temperature in 96well Protein LoBind plates (Eppendorf, Hamburg, Germany).

The cAMP synthesis of heterologously expressed sAC in HEK293 lysates was induced by applying di-sodium-ATP (Sigma Aldrich) and $\mathrm{MgCl}_{2}$ or $\mathrm{MnCl}_{2}$ in isotonic HEPES buffer. If not otherwise stated, reaction buffer contained (in mM): 1 ATP, $5 \mathrm{MgCl}_{2}$ or $5 \mathrm{MnCl}_{2}, 0.3$ $\mathrm{CaCl}_{2}, 120 \mathrm{KCl}, 12 \mathrm{NaCl}, 0.2 \mathrm{IBMX}, 50 \mathrm{HEPES} / \mathrm{KOH}$ (at $\mathrm{pH} 7$ or $\mathrm{pH}$ 8), and optional 25 $\mathrm{HCO}_{3}$. Reaction time was 10 minutes for assays with HEK293 lysates.

For cAMP quantification using the catch-point assay, reactions were stopped by quenching with $0.5 \times$ reaction volume $\mathrm{HClO}_{4}(1.5 \mathrm{M})$. The solution was neutralized with $0.625 \times$ reaction volume $\mathrm{K}_{3} \mathrm{PO}_{4}(1 \mathrm{M})$. Salt precipitate and cell debris were removed by centrifugation of the $96-w e l l$ plates $\left(10 \mathrm{~min}, 4,000 \times \mathrm{g}, 4^{\circ} \mathrm{C}\right)$. The supernatant was transferred into a new 96well plate.

The total content of cAMP in quenched samples was determined by using the CatchPoint cAMP Fluorescent Assay Kit (Molecular Devices, San Jose, USA) with some modifications, in particular to adjust reactions volumes to the 8- or 12-channel pipettes (Eppendorf, Hamburg, Germany), repetitive pipette HandyStep (Brand, Wertheim, Germany), or the Multi-Channel Auto Sampling System NSP-7000 (Nichiryo, Japan). Briefly, $60 \mu 1$ of the quenched sample and $50 \mu \mathrm{l}$ each of the anti-cAMP antibody and the HRP-cAMP conjugate were applied to an anti-rabbit IGG-coated 96-well plate according to the manufacturer's protocol. After 90 min of incubation at room temperature and repetitive washing (3 times) with wash buffer (125 $\mu$ l each), the Stoplight Red Substrate (125 $\mu 1)$ was applied to monitor the immunoreaction. The 96-well plates were analyzed using a FLUOstar Omega microplate reader (BMGLabtech, Ortenberg, Germany). The amount of cAMP was quantified using calibration curves obtained by serial dilutions of cAMP standards. Analysis was done using 
the reader's data analysis software MARS. Further data processing was done using Excel (Microsoft, USA) and OriginPro (Origin lab, USA). Figures were prepared using CorelDrawX6 and Photo-PaintX6 software (Corel Corporation).

The cAMP content of intact HEK293 cells stably expressing $R n \mathrm{sAC}_{\mathrm{t}}\left(2.0 \times 10^{6}\right.$ cells $)$ was determined by an accumulation assay (58). Cells were transferred to $1.5 \mathrm{ml}$ tubes and incubated in DMEM $+10 \%$ FBS in suspension at $37^{\circ} \mathrm{C}, 5 \% \mathrm{CO}_{2}$ for one hour. A time zero value for each condition was determined by adding $100 \mu \mathrm{l}$ of cells directly into $100 \mu \mathrm{l}$ stop solution $(0.2 \mathrm{M} \mathrm{HCl})$. To measure cAMP accumulation, cells in suspension were incubated for the indicated period of time in the presence of $500 \mu \mathrm{M}$ IBMX and $30 \mu \mathrm{M}$ TDI-8164 at $37^{\circ} \mathrm{C}$ after which $100 \mu \mathrm{l}$ of cells were transferred to a fresh tube containing stop solution. Intracellular cAMP content was determined using Correlate-EIA Direct Assay (Assay Designs, Inc).

\section{Measurement of changes in $\mathrm{V}_{\mathrm{m}}, \mathrm{pH}$, and $\left[\mathrm{Ca}^{2+}\right]_{\mathrm{i}}$, in $\mathrm{A}$. punctulata sperm}

We measured changes in $\mathrm{Ca}^{2+}, \mathrm{pH}_{\mathrm{i}}$, and $\mathrm{V}_{\mathrm{m}}$ by loading sperm samples with the corresponding dyes (Fluo-4AM, BCECF-AM, or pHrodo Red-AM from Molecular Probes, Eugene, USA, and FluoVolt from Thermofisher) and subsequent mixing in a rapid-mixing device (SFM-400, BioLogic, Claix, France) (27). Dry sperm was suspended 1:6 (v/v) in artificial seawater (ASW) containing (in mM): $\mathrm{NaCl} 423, \mathrm{CaCl}_{2}$ 9.27, $\mathrm{KCl}$ 9, $\mathrm{MgCl}_{2}$ 22.94, $\mathrm{MgSO}_{4}$ 25.5, EDTA 0.1, HEPES 10 at $\mathrm{pH} 7.8$, and the respective dye $\left(18^{\circ} \mathrm{C}\right)$. Loading concentrations and times were: Fluo-4AM: $10 \mu \mathrm{M}$ for 30-45 min (0.5\% Pluronic F127, Molecular Probes); BCECFAM: $10 \mu \mathrm{M}$ for 10 min; pHrodo Red-AM: $10 \mu \mathrm{M}$ for 30-45 min (0.5\% Pluronic F127). After 1:20 (v/v) dilution in ASW, sperm were allowed to equilibrate for 5 min. Subsequently, sperm were mixed 1:1 (v/v) with ASW. The 1:20 dilution experiments were performed by incubating sperm with the respective indicator in ASF (1:6). Sperm were then loaded into the stopped-flow device and rapidly mixed (1:20 dilution) with either ASF or ASW. The 1:2- 
dilution experiments were performed by incubating the sperm with the respective indicator in ASF (1:6), followed by 1:20 dilution in ASF. The diluted sperm suspension was then loaded into the stopped-flow device and rapidly mixed 1:2 with either ASF, 0KASW7.8 (ASW with no $\mathrm{K}^{+}$present), or 30KASW7.8 (ASW with $30 \mathrm{mM} \mathrm{K}^{+}$). When mixing with 0KASW7.8, the final $\left[\mathrm{K}^{+}\right]$was $10 \mathrm{mM}$, i.e. similar to normal ASW; the final $\mathrm{pH}_{\mathrm{o}}$ was about 7.75. When mixing with $30 \mathrm{KASW} 7.8$, the final $\left[\mathrm{K}^{+}\right]$was $30 \mathrm{mM}$ and the final $\mathrm{pH}_{\mathrm{o}}$ was 7.75 . All signals obtained upon dilution of 1:2 and 1:20 in the stopped-flow were recorded at flow rates of $2 \mathrm{ml} \mathrm{s}^{-1}$.

Fluorescence was excited by pulsed LED light (SpectraX Light Engine, Lumencor, Beaverton, USA or M490L3, Thorlabs, Newton, USA) with a frequency of $10 \mathrm{kHz}$. Emission was recorded by photo-multiplier modules (H9656-20 and C7169, Hamamatsu Photonics, Japan). The signal was amplified and filtered by a lock-in amplifier (7230 DualPhase, Ametek, Paoli, USA). Data acquisition was performed with a data acquisition pad (PCI-6221, National Instruments, Austin, USA) and Biokine Software v.4.49 (BioLogic). Fluo-4 was excited using 490/20 nm filter (Semrock) and its emission collected using a 536/40 nm filter (Semrock); BCECF was excited using a 452/45 nm filter (Semrock). BCECF fluorescence was recorded in dual-emission mode using Brightline 494/20 nm and 540/15 nm filters (Semrock). The $\mathrm{pH}_{\mathrm{i}}$ signals represent the ratio of F494/F540. All signals are the average of at least two recordings and are depicted as the percent change in ratio $(\Delta \mathrm{R} / \mathrm{R})$ with respect to the first 10-20 data points after mixing. The pHrodo Red dye was excited at 572/15 nm and the emission was collected at 628/40 nm. Fluovolt was excited using a 513/18 nm filter (Semrock) and its emission collected at 540/20 nm (Semrock). Di-8-ANEPPS was exited at 475/20 nm (Semrock) and its fluorescence was recorded in dual-emission mode using Brightline 536/40 nm and 628/40 nm filters (Semrock). The $\mathrm{V}_{\mathrm{m}}$ signals (ratio 536/549 nm (R); average of at least four recordings) are depicted as the percent change in ratio $(\Delta R / R)$ 
with respect to the first 10 data points. The signal recorded upon mixing sperm with ASF represented the baseline control and was subtracted from the respective signals. To manipulate cGMP in sperm during chemoattractant stimulation, sperm were incubated with $15 \mu \mathrm{M}$ DEACM-caged cGMP for $7 \mathrm{~min}$ in the presence of $0.25 \%$ Pluronic $^{\mathrm{TM}} \mathrm{F}-127$ (ThermoFisher). Uncaging was performed in the stopped-flow cuvette by a $360 \mathrm{~nm}$ LED (Thorlabs) with arbitrary waveforms (27).

\section{Measurements of $\mathrm{pH}_{\mathrm{i}}$ in different compartments of single sperm cells}

Sperm (1:25 dilution) were incubated for $30 \mathrm{~min}$ at $20^{\circ} \mathrm{C}$ in $\mathrm{ASW}$ containing $20 \mu \mathrm{M}$ pHrodo Red-AM (Molecular Probes) and 0.5\% Pluronic F127 (Sigma-Aldrich). After labelling, sperm were diluted (1:100 dilution) and loaded into glass capillaries for perfusion (Rectangle Boro Tubing 0.2x $4 \mathrm{~mm}$; Vitro Tubes). $\mathrm{pH}$ signals were calibrated using the $\mathrm{pH}_{\mathrm{i}}$ "pseudo-null point" method as previously described (27) using different ratios of a weak acid (propionic acid; $\mathrm{pK}_{\mathrm{a}}=4.88$ ) and a weak base (ammonium chloride; $\left.\mathrm{pK}_{\mathrm{a}}=9.24\right)$. $\mathrm{pHrodo}$ Red fluorescence was recorded with an inverted microscope (Olympus IX71) equipped with a 20x objective lens (UPlanSApo 20x, 0.75 NA; Olympus) and a 560 DCXR dichroic mirror (Chroma). Stroboscopic imaging of the rapid flagellum was achieved using a multicolor lamp (2 ms light pulses; Spectra X Light Engine; Lumencor). To accommodate for the large difference of emission intensity between head and flagellum, we used two alternating excitation wavelengths and excitation band-pass filers. Green excitation (ET545/30; Chroma) was used to image the sperm flagellum and Teal excitation (FF01-513/17; Chroma) for imaging of the head. Emission light was filtered using a band-pass filter (BA575-625; Olympus) and images were collected using an EMCCD camera (DU-897D; Andor Technology). Quantification of signals was done using custom-made software written in Matlab (Mathworks). Sperm cells were perfused with different null-point solutions, and the fluorescence intensity was recorded. pHrodo Red intensity was averaged for 30 frames before 
and after perfusion with the null-point solutions. To evaluate the resting $\mathrm{pH}_{\mathrm{i}}$, a least-meansquare method was used. For this, individual points were weighted by the inverse of their s.e.m.

\section{Emulation of spawning in the stopped-flow device}

Spawning was emulated in the stopped-flow device by two different approaches. Dry sperm was incubated 1:6 in artificial seminal fluid (ASF), containing the respective indicator dyes. ASF was ASW at pH 6.7 containing $30 \mathrm{mM}\left[\mathrm{K}^{+}\right]$. After incubation, the sperm suspension was diluted 1:20 in ASF. In the stopped-flow device the suspension was rapidly mixed with $\mathrm{K}^{+}-$ free ASW that was fortified with $50 \mathrm{mM}$ Hepes at $\mathrm{pH}$ 7.8. After 1:2 mixing the $\left[\mathrm{K}^{+}\right]$was 10 $\mathrm{mM}$ and $\mathrm{pH}$ was 7.7-7.8. Alternatively, dry sperm was incubated 1:6 in ASF and then mixed 1:40 with ASW in the stopped-flow device.

\section{The pH-clamp method}

We determined the $\mathrm{pH}_{\mathrm{i}}$ sensitivity of the alkaline-induced $\mathrm{Ca}^{2+}$ influx using the " $\mathrm{pH}_{\mathrm{i}}$ pseudonull-point” method (34, 60-62) (Bond and Varley, 2005; Chow et al., 1996; Eisner et al., 1989; Swietach et al., 2010) that allows clamping of $\mathrm{pH}_{\mathrm{i}}$ to fixed values and calibration of the $\mathrm{pH}$ indicator BCECF. The method for sea urchin sperm is described in $(24,27)$. Key is a set of $\mathrm{pH}_{\mathrm{i}}$-clamp solutions composed of a weak acid (butyric acid, BA) and a weak base (trimethylamine, TMA) at different molar ratios. TMA and BA freely equilibrate across the membrane and, at sufficiently high concentrations, establish a defined $\mathrm{pH}_{\mathrm{i}}$ that is set by the acid/base ratio (61). The $\mathrm{pH}_{\mathrm{i}}$-null-point solutions were prepared according to the following equation: $\mathrm{pH}_{\mathrm{i}-\text { null }}=\mathrm{pH}_{\mathrm{o}}-0.5 \log ([\mathrm{BA}] /[\mathrm{TMA}]) ; \mathrm{pH}_{\mathrm{o}}=\operatorname{extracellular} \mathrm{pH}(7.8)(34)$, wherein [TMA] indicates the concentration of trimethylamine and [BA] that of butyric acid. The [BA] was $15 \mathrm{mM}$. 


\section{Measurement of sperm motility}

Sperm motility was recorded in an inverted microscope (Olympus IX71) equipped with a 10x objective lens (UPlanSApo 10x, 0.4 NA; Olympus) under dark-field illumination at $25 \mathrm{~Hz}$ (sea urchin sperm) or $40 \mathrm{~Hz}$ (salmon sperm) with an EMCCD camera (DU-897D; Andor Technology). Arbacia punctulata sperm were diluted 1:200 in artificial seminal fluid (ASF) containing 0.5\% Pluronic F127 (Sigma-Aldrich) and loaded into glass capillaries for superfusion (Rectangle Boro Tubing 0.2x4 mm; Vitro Tubes). The 150-mm loading tube (0.86 mm ID, $1.52 \mathrm{~mm}$ OD Fine Bore Polythene Tubing; Smiths medical) was then placed into artificial seawater (ASW) with $0.5 \%$ Pluronic F127 to prevent sticking to the glass surface. Starting the perfusion results in mixing ASF with sperm and replacing the ASF with ASW. After dilution of the sperm suspension by 1:100 in ASW, the perfusion was stopped and the time course of activation was recorded. Quantification of the number of activated cells at different time points was done using custom-made CASA software written in MATLAB (Mathworks).

Salmon salar sperm (dilution 1:2770) were loaded for five minutes in salmon ASF containing $4 \mu \mathrm{M}$ DEACM-caged cAMP and 0.5\% Pluronic F127 (Sigma-Aldrich). Incubations were discarded after 30 minutes. For imaging, sperm were loaded into custom-made glass chambers with $150 \mu \mathrm{m}$ height. A 390-nm light source (SpectraX Light Engine; Lumencor) was used to release cAMP. The power of the UV (147 $\mathrm{mW}$ maximal power) was measured using a power meter (Controller PowerMax and head model PS19Q; Coherent). The flash intensity was graded using neutral density filters (Absorptive ND Filters; Thorlabs), and the duration of the flash (5 ms length) was controlled using a custom-made LabVIEW software. The percentage of cAMP released was calculated based on the photochemical properties of DEACM-caged cAMP (63) and the light intensity at the focal plane of the microscope. The motility indicator was calculated using custom-made software written in MATLAB 
10.06 .2021

(Mathworks). In brief, the software binarizes the images using an automatic threshold (graythres). Sperm motility can be coarsely quantified by subtracting temporally-adjacent frames. The absolute value of this image difference is then integrated to produce a motility score. When sperm are perfectly static, such score becomes zero and gradually increases as cells move. The relative sperm density was quantified as the mean pixel intensity of the binarized image. To compensate for slight variations in sperm density, this value was used to normalize the motility score.

\section{Data Availability}

All relevant data are available from the authors upon request. 
bioRxiv preprint doi: https://doi.org/10.1101/2021.06.18.448929; this version posted June 18, 2021. The copyright holder for this preprint (which was not certified by peer review) is the author/funder. All rights reserved. No reuse allowed without permission.

10.06 .2021

\section{References}

1. Levin LR \& Buck J (2015) Physiological roles of acid-base sensors. Annu. Rev. Physiol. 77:347362.

2. De Jonge C (2017) Biological basis for human capacitation-revisited. Hum. Reprod. Update 23(3):289-299.

3. Esposito G, et al. (2004) Mice deficient for soluble adenylyl cyclase are infertile because of a severe sperm-motility defect. Proc. Natl. Acad. Sci. USA 101:2993-2998.

4. Nolan MA, et al. (2004) Sperm-specific protein kinase A catalytic subunit $\mathrm{C}_{2}$ orchestrates cAMP signaling for male fertility. Proc. NatI. Acad. Sci. USA 101:13483-13488.

5. Xie F, et al. (2006) Soluble adenylyl cyclase (SAC) is indispensable for sperm function and fertilization. Dev. Biol. 296:353-362.

6. Akbari A, et al. (2019) ADCY10 frameshift variant leading to severe recessive asthenozoospermia and segregating with absorptive hypercalciuria. Hum. Reprod. 34(6):11551164.

7. Vacquier VD, Loza-Huerta A, Garcia-Rincon J, Darszon A, \& Beltran C (2014) Soluble adenylyl cyclase of sea urchin spermatozoa. Biochim. Biophys. Acta. 1842(12 Pt B):2621-2628.

8. Rafati N, et al. (2020) Reconstruction of the birth of a male sex chromosome present in Atlantic herring. Proc. Natl. Acad. Sci. USA.

9. Trötschel C, et al. (2020) Absolute proteomic quantification reveals design principles of sperm flagellar chemosensation. EMBO J. 39(4):e102723.

10. Windler $\mathrm{F}$, et al. (2018) The solute carrier SLC9C1 is a $\mathrm{Na}^{+} / \mathrm{H}^{+}$-exchanger gated by an S4-type voltage-sensor and cyclic-nucleotide binding. Nat. Comm. 9(1):2809.

11. Wobig L, et al. (2020) A family of hyperpolarization-activated channels selective for protons. Proc. Natl. Acad. Sci. USA.

12. Gauss R, Seifert R, \& Kaupp UB (1998) Molecular identification of a hyperpolarization-activated channel in sea urchin sperm. Nature 393:583-587.

13. Beltrán C, et al. (2007) Particulate and soluble adenylyl cyclases participate in the sperm acrosome reaction. Biochem. Biophys. Res. Commun. 358:1128-1135.

14. Tresguerres M, et al. (2010) Bicarbonate-sensing soluble adenylyl cyclase is an essential sensor for acid/base homeostasis. Proc. Natl. Acad. Sci. USA 107(1):442-447.

15. Kleinboelting $S$, et al. (2014) Crystal structures of human soluble adenylyl cyclase reveal mechanisms of catalysis and of its activation through bicarbonate. Proc. Natl. Acad. Sci. USA 111(10):3727-3732.

16. Kleinboelting S, et al. (2016) Bithionol Potently Inhibits Human Soluble Adenylyl Cyclase through Binding to the Allosteric Activator Site. J. Biol. Chem. 291(18):9776-9784.

17. Ramos-Espiritu L, et al. (2016) Discovery of LRE1 as a specific and allosteric inhibitor of soluble adenylyl cyclase. Nat. Chem. Biol. 12(10):838-844.

18. Steegborn C (2014) Structure, mechanism, and regulation of soluble adenylyl cyclases similarities and differences to transmembrane adenylyl cyclases. Biochim. Biophys. Acta. 1842(12 Pt B):2535-2547.

19. Steegborn C, Litvin TN, Levin LR, Buck J, \& Wu H (2005) Bicarbonate activation of adenylyl cyclase via promotion of catalytic active site closure and metal recruitment. Nat. Struct. Mol. Biol. 12:32-37.

20. Buck J \& Levin LR (2014) The role of soluble adenylyl cyclase in health and disease. Biochim. Biophys. Acta 1842(12 Pt B):2533-2534.

21. Jaiswal BS \& Conti M (2001) Identification and functional analysis of splice variants of the germ cell soluble adenylyl cyclase. $J B C 276: 31698-31708$.

22. Chaloupka JA, Bullock SA, lourgenko V, Levin LR, \& Buck J (2006) Autoinhibitory regulation of soluble adenylyl cyclase. Mol. Reprod. Dev. 73(3):361-368.

23. Nishigaki T, et al. (2014) Intracellular pH in sperm physiology. Biochem. Biophys. Res. Commun. 450(3):1149-1158. 
bioRxiv preprint doi: https://doi.org/10.1101/2021.06.18.448929; this version posted June 18, 2021. The copyright holder for this preprint (which was not certified by peer review) is the author/funder. All rights reserved. No reuse allowed without permission.

10.06 .2021

24. Seifert R, et al. (2015) The CatSper channel controls chemosensation in sea urchin sperm. EMBO J. 34:379-392.

25. Balbach $M$, et al. (2020) Optimization of lead compounds into on-demand, nonhormonal contraceptives: leveraging a public-private drug discovery institute collaborationdagger. Biol. Reprod. 103(2):176-182.

26. Bookbinder LH, Moy GW, \& Vacquier VD (1990) Identification of sea urchin sperm adenylate cyclase. J. Cell Biol. 111:1859-1866.

27. Hamzeh $\mathrm{H}$, et al. (2019) Kinetic and photonic techniques to study chemotactic signaling in sea urchin sperm. Meth. Cell Biol. 151:487-517.

28. Kaupp UB, et al. (2003) The signal flow and motor response controling chemotaxis of sea urchin sperm. Nat. Cell Biol. 5:109-117.

29. Harumi T, Hoshino K, \& Suzuki N (1992) Effects of sperm-activating peptide I on Hemicentrotus pulcherrimus spermatozoa in high potassium sea water. Develop. Growth \& Differ. 34:163-172.

30. Bönigk W, et al. (2009) An atypical CNG channel activated by a single cGMP molecule controls sperm chemotaxis. Sci. Signal. 2(94):ra68.

31. Strünker T, et al. (2006) A K $\mathrm{K}^{+}$-selective cGMP-gated ion channel controls chemosensation of sperm. Nat. Cell Biol. 8:1149-1154.

32. Lee $\mathrm{HC}$ (1984) A membrane potential-sensitive $\mathrm{Na}^{+}-\mathrm{H}^{+}$exchange system in flagella isolated from sea urchin spermatozoa. J. Biol. Chem. 259:15315-15319.

33. Nishigaki T, Zamudio FZ, Possani LD, \& Darszon A (2001) Time-resolved sperm responses to an egg peptide measured by stopped-flow fluorometry. Biochem. Biophys. Res. Commun. 284:531-535.

34. Eisner DA, et al. (1989) A novel method for absolute calibration of intracellular pH indicators. Pflugers Arch. 413(5):553-558.

35. Beltrán C, Zapata O, \& Darszon A (1996) Membrane potential regulates sea urchin sperm adenylyl cyclase. Biochemistry 35:7591-7598.

36. Alavi SM \& Cosson J (2006) Sperm motility in fishes. (II) Effects of ions and osmolality: a review. Cell Biol. Int. 30(1):1-14.

37. Kholodny V, Gadêlha H, Cosson J, \& Boryshpolets S (2019) How do freshwater fish sperm find the egg? The physicochemical factors guiding the gamete encounters of externally fertilizing freshwater fish. Reviews in Aquaculture:1-28.

38. Brokaw CJ (1984) Cyclic AMP-dependent activation of sea urchin and tunicate sperm motility. Ann. N. Y. Acad. Sci. 438:132-141.

39. Christen R, Schackmann RW, \& Shapiro BM (1982) Elevation of the intracellular pH activates respiration and motility of sperm of the sea urchin, Strongylocentrotus purpuratus. J.Biol.Chem. 257:14881-14890.

40. Johnson CH, Clapper DL, Winkler MM, Lee HC, \& Epel D (1983) A volatile inhibitor immobilizes sea urchin sperm in semen by depressing the intracellular pH. Dev. Biol. 98:493-501.

41. Cann MJ, Hammer A, Zhou J, \& Kanacher T (2003) A defined subset of adenylyl cyclases is regulated by bicarbonate ion. J. Biol. Chem. 278(37):35033-35038.

42. Chen $Y$, et al. (2000) Soluble adenylyl cyclase as an evolutionarily conserved bicarbonate sensor. Science 289:625-628.

43. Forchhammer K \& Selim KA (2020) Carbon/nitrogen homeostasis control in cyanobacteria. FEMS Microbiol. Rev. 44(1):33-53.

44. Berner RA (1990) Atmospheric carbon dioxide levels over phanerozoic time. Science 249(4975):1382-1386.

45. Selim KA, Haase F, Hartmann MD, Hagemann M, \& Forchhammer K (2018) PII-like signaling protein SbtB links cAMP sensing with cyanobacterial inorganic carbon response. Proc. Natl. Acad. Sci. USA 115(21):E4861-E4869.

46. Brokaw CJ (1987) Regulation of sperm flagellar motility by calcium and cAMP-dependent phosphorylation. J. Cell Biochem. 35(3):175-184. 
bioRxiv preprint doi: https://doi.org/10.1101/2021.06.18.448929; this version posted June 18, 2021. The copyright holder for this preprint (which was not certified by peer review) is the author/funder. All rights reserved. No reuse allowed without permission.

10.06 .2021

47. Christen R, Schackmann RW, \& Shapiro BM (1983) Metabolism of sea urchin sperm. Interrelationships between intracellular pH, ATPase activity, and mitochondrial respiration. $J$. Biol. Chem. 258:5392-5399.

48. King SM (2000) The dynein microtubule motor. BBA 1496:60-75.

49. Galindo BE, Neill AT, \& Vacquier VD (2005) A new hyperpolarization-activated, cyclic nucleotide-gated channel from sea urchin sperm flagella. Biochem. Biophys. Res. Commun. 334:96-101.

50. Wang $D$, et al. (2007) A sperm-specific $\mathrm{Na}^{+} / \mathrm{H}^{+}$exchanger (SNHE) is critical for expression and in vivo bicarbonate regulation of the soluble adenylyl cyclase (sAC). Proc. Natl. Acad. Sci. USA 104:9325-9330.

51. Wang D, King SM, Quill TA, Doolittle LK, \& Garbers DL (2003) A new sperm-specific $\mathrm{Na}^{+} / \mathrm{H}^{+}$ exchanger required for sperm motility and fertility. Nat. Cell Biol. 5:1117-1122.

52. Balbach $\mathrm{M}$, et al. (2020) Molecular Mechanism Underlying the Action of Zona-pellucida Glycoproteins on Mouse Sperm. Front. Cell Dev. Biol. 8(873).

53. Jansen V, et al. (2015) Controlling fertilization and cAMP signaling in sperm by optogenetics. Elife 4.

54. Smith KE, et al. (2019) Sea urchin reproductive performance in a changing ocean: poor males improve while good males worsen in response to ocean acidification. Proc. Biol. Sci. 286(1907):20190785.

55. Sali A \& Blundell TL (1993) Comparative protein modelling by satisfaction of spatial restraints. J. Mol. Biol. 234(3):779-815.

56. Schüttelkopf AW \& van Aalten DM (2004) PRODRG: a tool for high-throughput crystallography of protein-ligand complexes. Acta. Crystallogr. D. Biol. Crystallogr. 60(Pt 8):1355-1363.

57. Buck J, Sinclair ML, Schapal L, Cann MJ, \& Levin LR (1999) Cytosolic adenylyl cyclase defines a unique signaling molecule in mammals. Proc. Natl. Acad. Sci. USA 96(1):79-84.

58. Zippin $\mathrm{JH}$, et al. (2013) $\mathrm{CO}_{2} / \mathrm{HCO}_{3}^{-}$- and calcium-regulated soluble adenylyl cyclase as a physiological ATP sensor. J. Biol. Chem. 288(46):33283-33291.

59. Salomon Y (1979) Adenylate cyclase assay. Adv. Cyclic Nucleotide Res. 10:35-55.

60. Bond J \& Varley J (2005) Use of flow cytometry and SNARF to calibrate and measure intracellular pH in NSO cells. Cytometry Part A 64(1):43-50.

61. Chow S, Hedley D, \& Tannock I (1996) Flow cytometric calibration of intracellular pH measurements in viable cells using mixtures of weak acids and bases. Cytometry 24(4):360367.

62. Swietach P, et al. (2010) Hydrogen ion dynamics in human red blood cells. J. Physiol. 588(Pt 24):4995-5014.

63. Hagen V, et al. (2001) Highly efficient and ultrafast phototriggers for CAMP and cGMP by using long-wavelength UV/Vis-activation. Angew. Chem. Int. Ed. 40:1046-1048.

64. Kamenetsky M, et al. (2006) Molecular details of cAMP generation in mammalian cells: a tale of two systems. J. Mol. Biol. 362(4):623-639.

65. Wachten S, Schlenstedt J, Gauss R, \& Baumann A (2006) Molecular identification and functional characterization of an adenylyl cyclase from the honeybee. J. Neurochem. 96:15801590. 